\title{
The behaviour of the power transmission tower subjected to horizontal
}

\section{support's movements}

\author{
Qianjin Shu ${ }^{1}$, Guanglin Yuan ${ }^{1}$, Zhaohui Huang ${ }^{2, *}$, Sheng $\mathrm{Ye}^{1}$ \\ 1 State Key Laboratory for Geomechanics \& Deep Underground Engineering, School of Mechanics \\ \& Civil Engineering, China University of Mining \& Technology, Xuzhou, Jiangsu 221116, China \\ 2 Department of Mechanical, Aerospace and Civil Engineering, College of Engineering, Design and \\ Physical Sciences, Brunel University, Uxbridge, Middlesex UB8 3PH, UK
}

\begin{abstract}
In this paper, two half-scaled test tower models for a typical $110 \mathrm{kV}$ single-circuit power transmission tower were designed and fabricated. The scaled test tower models were tested under the horizontal support's stretching (tensile) and compressive movements with the normal working loading conditions. The deformations of the tested tower models and stresses within the different bracing members were fully measured. A large amount of comprehensive test data was generated. Also a finite element (FE) model using software ANSYS was developed and validated by the test data. The research indicated that the designed half-scaled test tower model can reasonably represent the behaviour of the whole transmission tower under the horizontal support's movements. The magnitude of the stresses was reduced from the bracing members at lower part to the bracing members at higher part of the tower. The effect of the ground surface deformations is more significant on the truss members closed to the supports. Hence, for the design of transmission tower against the horizontal support's movements, it is important to reduce the slenderness of those bracing members.
\end{abstract}

Keywords: Power transmission tower; horizontal support's movements; scaled test tower model; FE analysis.

\footnotetext{
2,* Corresponding author.

E-mail address: zhaohui.huang@brunel.ac.uk (Z. Huang)
} 


\section{Highlights:}

$>$ Design a scaled test tower model for a typical $110 \mathrm{kV}$ power transmission tower;

Conduct two tests on the scaled test tower model under the support's movements;

$>$ Develop a FE model using ANSYS for modelling the $110 \mathrm{kV}$ power transmission tower. 


\section{Introduction}

With the increasing demands on electric power supply, more and more power circuits have been developed in the serious geological disaster areas, such as coal mining areas, massive backfilling areas, and frost heaving soil or in permafrost soil areas [1-3]. These geological disasters cause the horizontal stretching or compressive movements, overall sinking and uneven settlement and deformation in the ground surface, which may break the ground circuits, even leading to power failure, relocation of power transmission tower, or re-routing power circuits [1]. In certain countries or areas, excessive excavation of coal resources has caused serious geological disasters, threatening the safe running of power supply. This problem has been much concern in engineering sectors [2]. The Island Creek Coal Company [4] in Virginia, USA, developed a grouting method to control the ground surface settlement and deformation in excavated areas to enable the coal mining under the pylons. Bruhn et al. [5] studied the structural response of a steel-lattice transmission tower to mining related ground movements. Bruce [6] investigated the impacts of underground coal mining on the surface constructions, including the pylons. Yuan et al. [7-8] studied numerically the influences of the ground surface deformations on the internal forces within the structure members of transmission tower, and also assessed the safety of the tower due to the ground surface deformation. An experiment investigation was also conducted on a scaled tower model of a $500 \mathrm{kV}$ power transmission tower subjected to the horizontal stretching followed by compressive deformation of the supports. Shu et al. [9] utilised FE method to analyse the failure modes of the transmission tower under various ground surface deformation conditions to obtain the displacement limits of the supports against various ground surface deformation conditions.

No doubt, full scale testing is very important on the determination of transmission tower type and their structural designs. At recent years, China Electric Power Research Institute conducted a full scale test on a $220 \mathrm{kV}$ power transmission tower with heavy ice load [10]. Prasad Rao et al. [11] conducted the full scale tests and FE analyses on the five power transmission towers of $132 \mathrm{kV}, 275 \mathrm{kV}$ and $400 \mathrm{kV}$ and compared the failure modes under various load combinations. The research indicated that the calculated load resistances of the 
tower structural members with different slenderness ratios by using ASCE code were greater than the test results. The load resistances of the cross bracing members calculated using BS specifications were less than but closer to the test data. However, the load resistances of the single bracing members calculated using BS code were still greater than the test results. Due to the unfavourable action, single bracing should be avoided in practice. The research also demonstrated that nonlinear analysis was superior to linear analysis for modelling the stress state and the failure mode of the truss structure.

Ahmed et al. [12] carried out a study on the influence of the slippage of bolted joints on the behaviour of transmission towers. The research indicated that the tower-leg joint slippage has a significant influence on tower behaviour by either reducing the load carrying capacity or significantly increasing the deflections under working loads. Yang et al. [13] developed a finite-element model by using the software ANSYS for modelling of a typical $1000 \mathrm{kV}$ transmission tower under different load cases, which included foundation settlement, slip, and inclination combined with normal design loads. The research indicated that the foundation deformations have considerable impacts to reduce load carrying capacity of the transmission towers.

At present, the majority of full scale tests for the transmission tower focused on the validation of the resistance of the tower structure under typical design loading conditions, such as normal working condition, wind condition, and ice covering condition. The full scale tests are very expensive and require a larger testing space and loading equipment. Also in the test, it is difficult to take into account the special undermining conditions. Fortunately, previous researches indicated that through scaled model tests and FE analyses, the deformation and failure mechanism of the transmission tower under different conditions can be reasonably assessed. Moona et al. [14] showed that half-scaled test model and FE analysis could reasonably reflect the structural response and deformation rule of the $152 \mathrm{kV}$ transmission tower. Xie and Sun [15] conducted two half-scaled test tower models for a $500 \mathrm{kV}$ transmission tower to investigate the deformation and failure of the tower structure under equivalent ice loading. In addition, the tests of scaled tower test model and FE analyses conducted in Refs. [7-9] also confirmed the feasibility of utilising scaled test tower models in 
structural analysis. Therefore, the tests on the scaled test tower model make it possible to study the deformation resistance of transmission towers in mining areas.

From the authors' knowledge, there is no any full scale test (for considering the structural resistance of the transmission tower subjected to the ground surface movements due to undermining) has been conducted. Hence, the main objectives of this research are:

- Develop a FE model using ANSYS for modelling the $110 \mathrm{kV}$ single-circuit power transmission tower subjected to the horizontal support's movements. Based on the FE analyses, two half-scaled test tower models to represent a typical $110 \mathrm{kV}$ single-circuit power transmission tower are designed and fabricated.

- Conduct two tests on the half-scaled test tower model to investigate the behaviour of the $110 \mathrm{kV}$ single-circuit power transmission tower subjected to horizontal support's movements under normal working condition. The corresponding failure modes, stress states in the structural members and the relationship between the deformations and support movements are studied in detail.

- Validate the developed FE model, using the test data, for modelling the full-scale $110 \mathrm{kV}$ single-circuit power transmission tower subjected to ground surface deformations.

\section{Design and fabrication of the scaled test tower model}

\subsection{Design of the scaled test tower model}

The prototype of the scaled test tower model is a typical $110 \mathrm{kV}$ single circuit Cat-head like 1B-ZM3 transmission tower. As shown in Fig. 1, the tower is $26.7 \mathrm{~m}$ high; the support spaces are $4.035 \mathrm{~m}$ perpendicular to the line direction and $3.125 \mathrm{~m}$ along the line direction. In order to design the scaled test tower model (substructure) which is a good representation of the full-scale tower, a FE model by using ANSYS was developed for modelling the full-scale tower subjected to horizontal supports' movements. The predicted overall deformations and stress states of the tower structure were analysed in detail to identify the influence scope within the tower, caused by the horizontal deformations of ground surface.

The results of FE analyses showed that the truss members within the bottom part of the tower were most susceptible to horizontal relative movements in the supports. The influences 
deceased upwards along the tower height. At above the second diaphragm member $(8 \mathrm{~m}$ up from the support's level, in Fig. 1) the influence due to ground surface deformations is negligible. According to the results of the FE analyses, the selection of steel angle members for the scaled test tower model, and available loading equipment in the lab, only part of the tower below the second diaphragm member was selected as the substructure for the scaled test tower model (in Fig. 1). The scale of the test tower model was set to be half-scaled $(1: 2)$, so the cross section area of the truss members for the scaled test tower model was $1 / 4$ of the cross section of the truss members for the original full-scale tower. As shown in Fig. 2, the height of the scaled test tower model was $4 \mathrm{~m}$, and the sizes of the top and bottom sections of the scaled test tower model were $2018 \times 1563 \mathrm{~mm}$ and $1530 \times 1200 \mathrm{~mm}$, respectively.

\subsection{Validation of the scaled test tower model}

In order to make sure that the selected substructure of the tower can reasonably represent the behaviour of the whole tower under the horizontal ground surface deformations, both the substructure and whole tower were analysed using ANSYS. Previous researches $[1,11,14,15]$ indicated that one of the main failure modes of transmission tower is the out-of-plane buckling of the cross bracing members. Due to the link element cannot model the out-of-plane buckling of the members hence, the beam element was adopted to represented the cross bracing members of the tower in their research. By using the beam element the behaviour of the cross bracing members can be more realistically modelled. Therefore in this research the tower legs and cross bracing members were modelled with Beam188 elements.

Normally the cross bracing members of transmission tower are connected to the tower legs through a bolt connection. This kind of joint has a relatively small stiffness to resist in-plane rotation. However, the cross-section of cross bracing members is relatively small and with thin-wall. Hence, a bolt connection has a considerable stiffness against out-of-plane rotation. As mentioned above the main failure mode of the cross bracing members is the out-of-plane buckling. The tests conducted in the current study further confirmed that there were no notable in-plane rotations observed at the connections between the cross bracing members and tower legs. Therefore this kind of joints cannot be properly modelled as pinned connections. Hence, in this study the connections of cross bracing members to tower legs have been represented as rigid connections for the FE modelling. This assumption is more properly to represent the real structural behaviours of the tower.

Only the auxiliary members were modelled with Link180 elements. Hence, the convergence 
problem induced by the link elements in static structural analysis was overcome in the finite element model developed here.

As mentioned above one of the main failure modes of transmission tower is the out-of-plane buckling of the cross bracing members subjected to compressive forces acting on the members. This is a typical geometric nonlinear problem. Therefore for the modelling of transmission tower the geometric nonlinear finite element model is needed.

In this FE model the bolt connections were modelled by coupling the nodal displacements of the intersection points. For the modelling of selected substructure, all members within the top section were modelled using beam elements to account for the constraint from the top structure of the tower.

In FE analysis only normal working condition (vertical loads) was considered. That is: at temperature of $15^{\circ} \mathrm{C}$; no wind and ice covering loads; only the self-weight of the tower, shield wires, conductors and insulators, and the earth wire were considered. Normal working loading conditions for the prototype whole tower is listed in Table 3, the load values were based on the recommendation in Ref. [16]. The equivalent vertical loads applied on the scaled test tower model (the substructure model) were calculated based on the same axial stress level at the cross-section of the tower legs at the ground level of the whole tower. The equivalent vertical loads were applied at the tops of the four tower legs of the substructure model.

Due to limited space, only the case with the horizontal tensile stretching of the supports in the direction perpendicular to the line is presented here. In this case, the horizontal distances between supports $A(D)$ and $B(C)$ (Fig. 2) were stretched. For the case with the compressive supports' movement, the horizontal distances between $\mathrm{A}(\mathrm{D})$ and $\mathrm{B}(\mathrm{C})$ (Fig. 2) were reduced.

Fig. 3 shows the comparison of predicted deformed shapes between the scaled test tower model and the original whole tower subjected to the horizontal stretching of the supports. It can be seen that similar deformations were happened within the substructure represented by the scaled test tower model for both FE analyses. The deformation was mainly related to the out-of-plane buckling of the first cross bracing member in the plane perpendicular to the line direction. The deformations were mostly happened around the first diaphragm member. There was no significant deformation around the second diaphragm member (Fig. 2 for the members' positions).

Fig. 4 shows the comparisons of the axial forces were changed with the displacements of the supports under horizontal stretching in some key members for both FE analyses. It is clear 
that the curves are closed to each other, especially before descending. The maximum support displacements at the peak axial forces for both analyses were $28.00 \mathrm{~mm}$ and $29.73 \mathrm{~mm}$, respectively, with only a difference of $5.82 \%$. Also, the difference between the peak axial forces of both analyses was within $10 \%$. Therefore, the structural behaviours between the scaled test tower model and the whole tower structure were very similar. Hence, the scaled test tower model can be confidently used to represent the whole tower structure in this research.

\subsection{Fabrication of the scaled test tower model}

In the prototype tower the tower legs were mainly made of hot rolled equal leg angles. Other diagonal, diaphragm and auxiliary members were made of cold worked angles. This was adopted for the scaled test tower model. The steel grade of the hot rolled angles was Q235 and the grade of the cold worked angles was Q235. The elastic modulus was $2.06 \times 10^{5} \mathrm{~N} / \mathrm{mm}^{2}$, and the Poisson's ratio was 0.3 . The cross sections of the different structural members for the prototype tower and scaled test tower model are presented in Table 1.

The scaled test tower models were fabricated by Jiangsu Huadian Tower Manufacturing Ltd of State Power Grid Corporation of China. The bolts used in the prototype whole tower were the Grade 4.8 galvanised M16 bolts. According to the scale of 1:2, the bolts used for substructure model should be not less than Grade $4.8 \mathrm{M} 8$ bolts. In order to avoid the premature failure of the joints caused by the bolts' stress concentration, in this study the Grade 8.8 galvanised M8 bolts were used. To keep the bolt pre-tightening force as constant, the tightening torque was controlled in accordance with the standards of magnitude $4.8 \mathrm{M} 8$ bolts. The yield torque of the Grade 8.8 galvanised M8 bolts was calculated based on the Chinese National Standard (GB/T 16823.2-1997), which was $18.1 \mathrm{Nm}$. Hence, in this research, the tightening torque of the bots for the scaled test tower model was set to be $18 \mathrm{~N} \mathrm{~m}$.

\subsection{Material properties of the scaled test tower model}

The material properties of the angles used for the scaled test tower model were tested on the MTS810 system. The average tested yield strengths for hot rolled and cold worked angles were given in Table 2. Fig. 5 shows the stress-strain relationship of the typical hot rolled angle specimen of $\mathrm{L} 40 \times 4$. 


\section{Test conditions of the scaled test tower model}

\subsection{Loading conditions}

The transmission tower located in the coal mining area is subjected to combined ground surface deformation and complex upper loading conditions. Normally, the upper loadings of the tower include normal operation working condition, non-uniform ice and wind load conditions. For the wind load condition it is needed to consider the magnitude of the wind speed, the influence of the direction of the wind. Therefore, it is a very challenge task to take into account all loading conditions in one experimental test. Hence, as the first stage of this research project a simple normal operation working condition was considered in the tests. That is: at temperature of $15{ }^{\circ} \mathrm{C}$; no wind and ice covering loads; only the self-weight of the tower, shield wires, conductors and insulators, and the earth wire were considered. This is one of the main three working conditions of the transmission tower recommended in Ref. [16] (as shown in Table 3).

As mentioned in Section 1, one of the main objectives of this paper is to develop a FE model using ANSYS for modelling the $110 \mathrm{kV}$ single-circuit power transmission tower subjected to the horizontal support's movements. The developed FE model will be validated using the test data generated from this research. Then the validated FE model will be used in the second stage of this research project to assess the behaviour of the $110 \mathrm{kV}$ single-circuit power transmission tower subjected to combined different working conditions, such as, non-uniform ice and wind load conditions, with ground surface deformations.

\subsection{Horizontal support's movements}

Ground surface deformations cause various supports' movements of transmission tower in mining areas. It is very difficult to represent those support conditions in lab's environment. However, previous research and engineering experience indicated that the horizontal stretching or compressive movements of the tower's supports were the most typical conditions which were frequently occurred and caused the failure of transmission tower due to excessive deformations of truss members of the towers in mining areas. Hence, this research was focused on the behaviour of the transmission tower under horizontal support's stretching (tensile) and compressive movements conditions. As shown in Figs. 6(a) and 6(b), the horizontal supports' displacements were confined to the vertical direction of the line.

In the tests for the tensile movement of the supports, the horizontal distances between 
supports $A(D)$ and $B(C)$ (Fig. 2) were stretched. For the case with the compressive supports' movement, the horizontal distances between supports $A(D)$ and $B(C)$ (Fig. 2) were reduced.

\section{Loading and measurement}

\subsection{Loading scheme}

Under normal working condition, the scaled test tower model withstands only the vertical loads, transferred from the upper part of the tower (the tower head, wires, earth wires, and shield wires, conductors and insulator). The vertical loads on the scaled test tower model were calculated as the 1/4 times of that on the prototype whole tower, which was based on the principle of equal axial compressive stress of the tower legs. As a result, the load magnitude applied to each tower leg was estimated to be around $350 \mathrm{~kg}$. In the test, the vertical loads were applied via a profile steel frame hanging on the four corners of the scaled test tower model.

As shown in Fig. 6(b), the horizontal motions of the supports of the scaled test tower model were generated through a special platform, made with two H-section steel beams. The four supports of the scaled test tower model were fixed on the two H-section steel beams with high strength bolts. Two jacks were mounted in between the two H-section beams ( Fig. 6(b)). The $\mathrm{H}$-section beam on one side of the platform was bolted to the ground as the fixed end and another H-section beam on the other side of the platform could be moved horizontally by the jacks. Steel rollers were placed under the moving H-section beam to facilitate the horizontal tensile supports' movements of the scaled test tower model (Fig. 6(b)). As shown in Fig. 6(b), the two jacks were mounted on a large fixed reaction beam outside of the H-section frame to generate the horizontal compressive displacement loading on the supports of the scaled test tower model.

\subsection{Measuring scheme}

The main parameters measured in the experiments include the displacements of the supports, displacements on the top of the scaled test tower model, the strains in the truss members and the reaction forces at the supports.

YHD-200 displacement meters were used to measure the displacements of the supports, one at each support along the direction perpendicular to the line. A total of four horizontal translational displacements of the supports were recorded. DH801-750 guyed displacement 
meters were used to measure the displacements on the top of the scaled test tower model. As shown in Fig. 7, 2 displacement meters were used at each top corner for detecting the horizontal displacements of the top corner along and perpendicular to the supports' displacement. There were total 8 DH801-750 guyed displacement meters were used at 4 top corners of the scaled test tower model. Those displacement meters were mounted on a steel pipe scaffold.

As mentioned in the previous sections the main failure mode of the cross bracing members of transmission tower is the out-of-plane buckling. Hence it is important to measure the axial compressive forces of these members. Normally, the average axial force of a member is calculated based on the average strain measured at the certain cross-section of that member. However, for axially compressed members, whether for the members with large slenderness ratios (buckling failure) or small slenderness ratios (strength failure), the maximum stress at some sections along the member may reach or exceed the yield stress when the member is in failure. If some parts of the cross-section reach to yield. Then it is not easy to accurately calculate average stress based on the measured strains. Therefore, in the tests for accurately measuring the axial forces of the compressive members it is important to make sure that the strain gauges are installed at the positions where the strains within the cross-section are either elastic or fully yield. In order to achieve this, in the current study, the locations of installed strain gauges along members were determined based on FE analysis. According to the results of the FE analyses, the locations of installed strain gauges were at the distances of $1 / 10-1 / 8$ of the members' total length from the end joints of the members. At those positions the flexure deformations of the members were negligible.

In this study, BX120-3AA strain gauges were used to measure the strains in the truss members. The arrangement of the strain gauges is illustrated in Fig. 8. The black filled dots along one of the tower legs (Fig. 8) mean that there were three strains gauges fixed at that position. Two of them fixed at each end of the flanges of the angle member, and the third one fixed at the corner of the angle member, as shown in Fig. 9(a). All three strains gauges were orientated in the axial direction of the angle member. The axial force and bending moment in the tower leg can be calculated using these three strains measured. For other measuring positions only two strain gauges were used. They were attached at each external surface of the angle member and orientated in the axial direction of the angle member for measuring the axial strains, as shown in Fig. 9(b). The reaction forces of the supports were measured by the pressure sensors which were mounted on the top of the jacks (Fig. 6(a)). 
For the all figures presented in the rest of this paper, the measured stresses were the average stresses of the cross-section of the members which were calculated from average measured strains, and the FE analysis stresses were calculated using the axial member force divided by the cross-section area of the member.

\section{Test procedure and observations}

\subsection{Testing procedure}

The tests were carried out in the structural lab of China University of Mining \& Technology (CUMT). The testing procedure was as follows:

(1) Assembling the H-section steel beams platform, mounting the scaled teste tower model onto the platform, adjusting the elevation for the supports of the scaled test tower model, mounting loading and measuring devices.

(2) Packing the steel loading blocks on the loading platform which applied the vertical loads on the four top corners of the scaled test tower model until the normal working loading condition was reached.

(3) Using jacks to apply the horizontal displacement loads on the two of the supports, (either tensile or compressive) with $1 \mathrm{~mm}$ loading step. After the relevant data readings became stable in each loading step, then started next loading step. The displacement load was increased step by step until significant deformation occurred in the truss members or the reaction forces exhibited dropping. All the measured parameters were recorded step by step by the computer via the data collection devices.

Fig. 10 shows the panorama view of the test.

\subsection{Observations}

\subsubsection{Horizontal support's stretching (tensile) test}

As shown in Fig. 8, the strain gauge' numbers are used as the truss member's numbers here for the rest of the paper. In this test, the horizontal spacing of the supports for the scaled test tower model was gradually increased in the direction normal to the line. When this support's tensile displacement was reached to $10 \mathrm{~mm}$, the first cross bracing (X-bracing) member parallel to the support displacement direction (F10 \& F11 and B7 \& B8, in Fig. 8) was 
exhibited slight out-of-plane buckling. When the support's displacement was reached to 40 $\mathrm{mm}$, the deformation in the truss members of the scaled test tower model became very significant (Figs. 11 and 12), and then the test was stopped. At this moment, the outward out-of-plane displacement of the first cross bracing member was about $80 \mathrm{~mm}$, undergoing significant local buckling near the centre bolted connection node of the angle (Fig. 13). The vertical displacement at the midpoint of the first horizontal diaphragm member (in Fig. 2 for the member position) was about $16 \mathrm{~mm}$. The tower legs had slight bending deformation. Apart from these, no visible deformations of other truss members were observed. Also the shear failures of the bolts were not observed as well.

Fig. 14 shows the relationship between the outward out-of-plane displacement at the first cross bracing joint (F10 and F11, in Fig. 8) and the support's displacement. The in-plane vertical displacement at the midpoint of the horizontal diaphragm member (F6, in Fig. 8) against the support's displacement is shown in Fig. 15.

\subsubsection{Horizontal support's compressive test}

In this case, the horizontal spacing of the supports for the scaled test tower model was gradually reduced in the direction normal to the line. When the support's compressive displacement was reached to $20 \mathrm{~mm}$, the bracing members F8 and B5 (Fig. 8) were exhibited slight bending deformations. When the support's compressive displacement was reached to 60 $\mathrm{mm}$, the out-of-plane deformations of the bracing members F8 and B5 became very significant (Fig. 16), then the test was stopped at this support's displacement loading. The inward out-of-plane deformation at the midpoint of the bracing member F8 was about $65 \mathrm{~mm}$ and the in-plane downward displacement was about $25 \mathrm{~mm}$. The deformation of the bracing member B5 was less than the one of member F8. The angle was buckled significantly at both ends of the bracing members F8 and B5. The connection plate, at the midpoint of the first horizontal diaphragm member, was bended slightly. The bracing members of F9 and B6 (Fig. 8) were exhibited slight bended deformations, far less than the bended deformations of the bracing members F8 and B5. As shown in Fig. 17, the in-plane deformation of the first horizontal diaphragm members F6 and B4 (Fig. 8) became significant, with the midpoint moved about $20 \mathrm{~mm}$ upwards. The second cross bracing of F12 \& F13 and B9 \& B10 (Fig. 8) were showed slight bended deformations. Apart from these, no visible deformations of other truss members were observed. Also the shear failures of the bolts were not observed as well. 


\section{Test results and analysis}

\subsection{Horizontal support's tensile test}

\subsubsection{Horizontal displacements at the top of the scaled test tower model}

As shown in Fig. 7, the displacements at the top of the scaled test tower model were measured by 8 guyed displacement meters (LVDT). LVDTs Nos. 1-4 were arranged paralleled to the support's displacement loading direction and LVDTs Nos. 5-8 were arranged perpendicular to the support's displacement loading direction. It was assumed that if the length of the cord of guyed displacement meter was reduced the measured value was positive and the measured value was negative if the length of the cord of guyed displacement meter was increased.

Fig. 18 shows the horizontal displacements at the top corners of the scaled test tower model versus the tensile support's displacements. It can be seen that the displacements at the top of the scaled test tower in the direction normal to the support's loading direction were very small and negligible. The displacements in the direction paralleled to the support's loading direction were increased almost linearly with the support's displacements. At the maximum support's displacement of $40 \mathrm{~mm}$ the horizontal displacements of the top corners in the direction paralleled to the support's loading direction were reached to $19.06 \mathrm{~mm}$. The maximum difference of the measured values between LVDTs No. 1 and No. 2 was $1.56 \mathrm{~mm}$, which is $0.13 \%$ of the length of the top horizontal diaphragm truss member normal to the support's displacement direction. The maximum difference of the measured values between LVDTs Nos. $1 \& 4$, and Nos. $2 \& 3$ was $0.48 \mathrm{~mm}$, which is $0.03 \%$ of the length of the top horizontal diaphragm truss member paralleled to the support's displacement direction. Hence, the test results indicated that the displacement of the tested tower top was mainly in the support's displacement loading direction. Therefore, under this displacement loading condition, the relative horizontal displacements between the four corners of the tower top were very small. Hence, there was no twisting deformation at the top horizontal plane of the scaled test tower model.

\subsubsection{Stresses in the truss members of the scaled test tower model}

In this tensile test, the truss members, within the panel F (front panel) and panel B (back panel) (Fig. 8) were mainly stressed. Fig. 19 shows the stresses of the cross bracing members versus the tensile support's displacements. Those stresses were calculated based on the measured average strains of the truss members. From the figure it can be seen that the first cross bracing members (F10 and F11) and the third cross bracing member (F14) (in Figs. 2, and 8 for the 
members' positions) were subjected to compression, whilst the second cross bracing members (F12 and F13) were subjected to tension. Therefore, the adjacent cross bracing members were exhibited "repeated compression-tension" state.

Due to the truss members of the transmission tower are mostly the members with large slenderness ratio; the main failure mode of the tower is the buckling failure of the truss members. As shown in Fig. 11, the cross bracing members F10 and F11 had significant buckling deformations. This was confirmed in Fig. 19 that the maximum compressive stresses of F10 and F11 were less than $80 \mathrm{MPa}$ which was well below the yield strength (235MPa) of Q235 steel.

The maximum stresses within the cross bracing members were reached when the support's displacement was around $12.5 \mathrm{~mm}$. After that, the compressive stresses of members F10 and F11 were reduced with further loading. This was caused by the buckling failure of the first cross bracing members as observed in the test. After the support's displacement was beyond about $27 \mathrm{~mm}$, the stress of member F14 was changed from compression to tension and the stresses of members F12 and F13 were changed from tension to compression. The possible reasons might be the slippage of the bolt joints or local buckling of certain truss members.

\subsection{Horizontal support's compressive test}

\subsubsection{Horizontal displacements at the top of the scaled test tower model}

Fig. 20 shows the horizontal displacements at the top corners of the scaled test tower model versus the compressive support's displacements. Similar to the tensile test, the horizontal displacements of the tower top were mainly along the support's loading direction and increased almost linearly with the support's displacements. At the maximum support's displacement of $60 \mathrm{~mm}$ the horizontal displacements of the top corners in the direction paralleled to the support's loading direction were reached to $31.98 \mathrm{~mm}$. Again, the test results indicated that the displacement of the tower top was mainly in the support's displacement loading direction and the relative horizontal displacements between the four corners of the tower top were very small. Hence, there was no twisting deformation at the top horizontal plane of the scaled test tower model.

\subsubsection{Stresses in the truss members of the scaled test tower model}

Similar to the tensile test, the main stressed truss members were within the panel $\mathrm{F}$ and panel B (Fig. 8) in this test. Fig. 21 shows the stresses of the bracing members F8, F10, F13 and F14 versus the compressive support's displacements. From the figure it can be seen that the 
bracing members F8 and F13 were subjected to compression, whilst the bracing members F10 and F14 were subjected to tension. Therefore, the adjacent diagonal members were exhibited "repeated compression-tension" state. The maximum stresses within the bracing members were reached when the compressive support's displacement was around $21 \mathrm{~mm}$. After that, the stresses of bracing members were reduced with further loading. This was caused by the buckling failure of the diagonal members above the first diaphragm (Fig. 2).

It can also be seen from Fig. 21 that there was a slight stress jump in the stressed members when the support's displacement reached to $28 \mathrm{~mm}$. The possible reason might be the slippage of the bolt joints.

\section{Validation of the developed FE model}

As mentioned in Section 2, a FE model by using ANSYS was developed to model the behaviours of the scaled test tower model and the original whole tower under ground surface deformation. Hence, in this section the two tests on the scaled test tower model were modelled, and the predicted results were compared with the test results to validate the accuracy of the developed FE model. Then the validated model will be used in the future to assess the behaviour of the $110 \mathrm{kV}$ single-circuit power transmission tower subjected to ground surface deformations and to improve the safety design of the tower under real working conditions.

\subsection{Modelling of the horizontal support's tensile test}

Fig. 22 shows the predicted deformations of the scaled test tower model. It can be seen that the largest deformation appeared within the first cross bracing (in Fig. 2 for the position) which is similar to the tested observation. Hence, in this test the predicted main failure mode of the scaled test tower model was the compressive buckling failure of the first cross bracing, which was also observed in the test.

Fig. 23 shows the comparison of the predicted and measured displacements at the position of the LVDT no. 3 against the tensile support's displacement. It can be seen that good agreement was achieved between predicted and tested displacements. When the support's displacement was $36 \mathrm{~mm}$, the difference between the FE prediction $(17.98 \mathrm{~mm})$ and the test measurement (16.84 mm) was less than $7 \%$.

Figs. 24-26 present the comparisons of the predicted and measured stresses within some key truss members. It is evident that the predicted and tested stress curves agreed reasonably 
well, especially in the initial loading stage. The predicted and tested peak stresses were appeared at the support's displacement of around $13.00 \mathrm{~mm}$.

The comparison of the predicted and measured maximum stresses within the cross bracing members was shown in Fig. 27. It can be seen that the magnitude of the stresses, either predicted or measured, was reduced from the lower bracing member ( $1^{\text {st }}$ bracing) to the higher bracing member ( $3^{\text {rd }}$ bracing). This indicates that effect of the ground surface deformation is more significant for the truss members closed to the supports. It is also known from Fig. 27 that the predicted maximum stresses of the three cross bracing members are bigger than the tested values. The peak stresses measured at the $1^{\text {st }}, 2^{\text {nd }}$ and $3^{\text {rd }}$ cross bracing members were $92 \%, 67 \%$ and $63 \%$ of the predicted values.

\subsection{Modelling of the horizontal support's compressive test}

The predicted deformations of the scaled test tower model are shown in Fig. 28 for this test. It can be seen from the figure that the most significant deformation was appeared within the diagonal bracing member F8 above the first horizontal diaphragm (Fig. 8). The second cross bracing member was deformed slightly. The main failure mode was the compressive stability failure of the diagonal bracing member F8 along the support's displacement direction, which was the same as the test observation.

In the modelling, the analysis was stopped when the compressive support's displacement was reached to $34 \mathrm{~mm}$ caused by the formation of a mechanism in the test tower. However, in the test, the test was stopped when the support's displacement reached to $60 \mathrm{~mm}$, to avoid collapsing of the test tower and no sudden increase of stress was observed.

Figs. 29-32 show the comparisons of the predicted and measured stresses within some key truss members. It can be seen that the measured and predicted stresses were agreed well in the initial stage. After the loaded compressive support's displacement was greater than $10 \mathrm{~mm}$ the discrepancies were increased. The predicted peak stresses of the bracing members were appeared when the compressive support's displacement was reached to around $17.00 \mathrm{~mm}$ $(21.07 \mathrm{~mm}$ in the test).

As shown in Fig. 33, the magnitude of the stresses, either predicted or measured, was reduced from the lower bracing member F8 to the higher bracing member F14. Same as the tensile test, the effect of the ground surface deformation is more significant on the truss members closed to the supports. The predicted peak stresses of all four bracing members were bigger than the test values. The measured maximum stresses of bracing members F8, F10, F13, and F14 were 
$85 \%, 72 \%, 78 \%$ and $73 \%$ of the predicted values, respectively.

\subsection{Discussions on the FE analysis of the transmission towers}

From the above validations, it is evident that the FE model with the geometric nonlinear can be used for analysis of the structural behaviour of the transmission towers under ground surface deformation. The FE model developed in this research can reasonably predict the deformations and failure mode of the whole tower structures subjected to ground surface movements. Hence, FE model is a powerful tool for the safety assessment of the transmission towers under different working conditions. The model can identify the maximum allowed support's tensile or compressive displacements for a certain transmission tower. Also the model can be used to predict maximum stresses and deformations within the bracing members of the tower to improve safety design of the tower to withstand specific ground surface deformation conditions.

It is also evident that compared to the test results, the FE model developed in this research predicts larger maximum stresses within the critical bracing members and less allowed the support's displacement for the tower. In general, for the construction of transmission tower, there are some structural defects existed in the structural members, assembly deviations and the deformed supports. Also the slippage of the bolts may happen under large loads and the deformations of the supports. Those factors were ignored in the current FE model. This may be the reasons why current FE model predicts larger maximum stresses within the critical bracing members and less allowed the support's displacement for the tower. This indicates that it is on the conservative side for using the developed FE model to assess the reliability of the transmission tower under ground surface movements.

Due to the limited space, this paper only presents the outcome of the first phase research of the project. The validated FE model will be used in the second stage of this research project to assess the behaviour of the $110 \mathrm{kV}$ single-circuit power transmission tower subjected to combined different working conditions, such as, non-uniform ice and wind load conditions, with ground surface deformations. Also a series of comprehensive parametric studies will be conducted. Based on the numerical results more rational design recommendations on the transmission tower subjected to ground movements will be proposed. The research outcomes 
will be presented in another paper.

\section{Conclusions}

In this research, two half-scaled test tower models for a typical $110 \mathrm{kV}$ single-circuit power transmission tower were designed and fabricated. The scaled test tower models were tested subjected to the horizontal tensile and compressive support's movements under the normal working loading conditions. The deformations of the scaled test tower models and stresses within the different bracing members were fully measured. A large amount of comprehensive test data was generated. The developed FE model was validated using the test data. The main conclusions are drawn as follows:

- The designed half-scaled test tower model can reasonably represent the behaviour of whole tower under the horizontal support's movements.

- For both tensile and compressive tests, the horizontal displacements of the tower top were mainly along the support's loading direction and increased almost linearly with the support's displacements. There was no twisting deformation at the top horizontal plane of the test tower.

- Under horizontal support's displacement loading conditions, the magnitude of the stresses, either predicted or measured, was reduced from the bracing members at lower part to the bracing members at higher part of the tower. The effect of the ground surface deformations is more significant on the truss members closed to the supports.

- Under normal working conditions, the main failure mode of the towers subjected to tensile support's displacement is compressive stability failure of the first cross bracing, whilst the main failure mode of the tower subjected to compressive support displacement is compressive stability failure of the diagonal bracing member above the first horizontal diaphragm (in Fig. 2 for the position). The failure of the tower legs was not seen in both tests. Hence, for the design of transmission tower against the horizontal support's movements, it is important to reduce the slenderness of those bracing members.

- The FE model developed in this research can be used (on the conservative side) to design the transmission tower against the ground surface movements. 


\section{Acknowledgements}

This research was supported by the Priority Academic Program Development of Jiangsu Higher Education Institutions. The authors gratefully appreciate this support.

\section{References}

[1] Yang F., Li Q., Yang J., Assessment on the stress state and the maintenance schemes of the transmission tower above goaf of coal mine. Engineering Failure Analysis, 2013, 31: 236-247.

[2] Jia L. and Zai H., Design and operation of power line in mining area, Beijing: China Electric Power Press, 2015. (in Chinese)

[3] Brown R.J.E., Permafrost in Canada-its influence on northern development. University of Toronto Press, 1973.

[4] Stump D.E. Jr., Grouting to control coal mine subsidence. Geotechnical Special Publication, Grouts and Grouting, 1998 (S1):128-138.

[5] Bruhn R. W., Ferrell, J.R., Luxbacher, G.W., The structural response of a steel-lattice transmission tower to mining related ground movements. Proceedings of the 10th International Conference on Ground Control in Mining, West Virginia University, Morgantown, WV, 1991: 301-306.

[6] White B. H., Outcomes of the independent inquiry into impacts of underground coal mining on natural features in the Southern Coalfield-An Overview. Proceedings of the 2009 coal operators conference, University of Uollongong, NSW, Austrilia, 2009: 112-123.

[7] Yuan G.L., Yang G.Y., Zhang Y.F., Regularities on internal force and structure deformation of transmission tower influenced by ground deformation, Journal of China Coal Society, 2009,34 (8): 1043-1047. (in Chinese)

[8] Yuan G.L., Zhang Y.F., Li S.M., Liu T., Ji Y.S., Model experiment on anti-deformation performance of self-supporting transmission tower in subsidence area, International Journal of Mining Science and Technology, 2012, 22(1), 57-62.

[9] Shu Q., Yuan G.L., Guo G., and Zhang Y., Limits to foundation displacement of an extra high voltage transmission tower in a mining subsidence area, International Journal of Mining Science and Technology, 2012, 22(1): 13-16.

[10] China Electric Power Research Institute. Testing report of a heavy iced ZB13-30 tower of the $220 \mathrm{kV}$ Shuicheng-Weining Transmission Line. Beijing: China Electric Power Research Institute, 2009. (in Chinese)

[11] Prasad Rao N., Samuel Knight G.M., Mohan, S.J., Lakshmanan N., Studies on failure of transmission line towers in testing, Engineering Structures, 2012, 35:55-70.

[12] Ahmed K.I.E., Rajapakse, R.K.N.D., Gadala, M.S., Influence of bolted-joint slippage on 
the response of transmission towers subjected to frost-heave, Advances in Structural Engineering, 2009, 12(1):1-17.

[13] Yang, F.L., Yang, J.B., Han, J.K., Zhang, Z.F. Study on the limited values of foundation deformation for a typical UHV transmission tower. IEEE Transactions on Power Delivery, 2010, 25(4): 2752-2758.

[14] Moona B.W. et al., Performance evaluation of a transmission tower by substructure test, Journal of Constructional Steel Research, 2009, 65:1-11.

[15] Xie Q. , Sun L., Failure mechanism and retrofitting strategy of transmission tower structures under ice load, Journal of Constructional Steel Research, 2012, 74:26-36.

[16]Liu Z.Y., The typical design of power transmission and transformation engineering in China State Grid Corp -Part of 110kV transmission line, China Electric Power Press, Beijing, 2005. 


\section{List of Tables and Figures}

Table 1 The sectional properties of the members for the prototype tower and scaled test tower model.

Table 2 The measured yield strength of the angles (MPa).

Table 3 Normal working loading conditions for the prototype whole tower.

Fig. 1 A prototype of $110 \mathrm{kV}$ single circuit transmission tower (all dimensions in $\mathrm{mm}$ ).

Fig. 2 The half-scaled test tower model (all dimensions in $\mathrm{mm}$ ).

Fig. 3 The comparison of predicted deformed shapes between the scaled test tower model and the original whole tower (enlarged 10 times).

Fig. 4 The comparisons of the axial forces of some key members for both FE analyses.

Fig. 5 Tested stress-strain curve of L $40 \times 4$ angle.

Fig. 6 The arrangements of the loading and horizontal support's movements along the direction perpendicular to the line.

Fig.7 Arrangement of 8 guyed displacement meters at 4 top corners of the scaled test tower model.

Fig. 8 The arrangement of the strain gauges in the truss members of the scaled test tower model.

Fig. 9 Details of the strain gauges attached on the structural members.

Fig. 10 Panorama view of the test.

Fig. 11 The deformations of the first cross bracing members.

Fig. 12 The deformations of the first diaphragm members.

Fig. 13 Angle buckling near the centre bolted connection node of the first cross bracing members.

Fig. 14 The outward out-of-plane displacement at the first cross bracing joint (F10-F11) against the support's displacement.

Fig. 15 The in-plane vertical displacement at the midpoint of the horizontal diaphragm member F6 against the support's displacement.

Fig. 16 The deformations of some key truss members.

Fig. 17 The deformations of the first horizontal diaphragm members F6 and B4.

Fig. 18 The horizontal displacements at the top corners of the scaled test tower model versus the tensile support's displacements (in Fig. 7 for the positions of the guyed meters).

Fig. 19 The stresses of the cross bracing members versus the tensile support's displacements.

Fig. 20 The horizontal displacements at the top corners of the scaled test tower model versus the compressive support's displacements (in Fig. 7 for the positions of the guyed meters). 
Fig. 21 The stresses of the cross bracing members versus the compressive support's displacements.

Fig. 22 The predicted deformations of the scaled test tower model (tensile test).

Fig. 23 The comparison of the predicted and measured displacements at the position of the LVDT no. 3 (tensile test).

Fig. 24 The comparison of the predicted and measured stresses within the first cross bracing member F11 (tensile test).

Fig. 25 The comparison of the predicted and measured stresses within the second cross bracing member F13 (tensile test).

Fig. 26 The comparison of the predicted and measured stresses within the third cross bracing member F14 (tensile test).

Fig. 27 The comparison of the predicted and measured maximum stresses within the cross bracing members (tensile test).

Fig. 28 The predicted deformations of the scaled test tower model (compressive test).

Fig. 29 The comparison of the predicted and measured stresses within the bracing member F8 (compressive test).

Fig. 30 The comparison of the predicted and measured stresses within the bracing member F10 (compressive test).

Fig. 31 The comparison of the predicted and measured stresses within the bracing member F13 (compressive test).

Fig. 32 The comparison of the predicted and measured stresses within the bracing member F14 (compressive test).

Fig. 33 The comparison of the predicted and measured maximum stresses within the cross bracing members (compressive test). 


\section{List of tables}

Table 1. The sectional properties of the members for the prototype tower and scaled test tower model

\begin{tabular}{|c|c|c|c|c|}
\hline \multirow{2}{*}{$\begin{array}{c}\text { Member } \\
\text { classification }\end{array}$} & \multicolumn{2}{|c|}{ Prototype tower } & \multicolumn{2}{|c|}{ Scaled test tower model } \\
\hline & $\begin{array}{l}\text { Section size } \\
(\mathrm{mm} \times \mathrm{mm})\end{array}$ & $\begin{array}{c}\text { Section area } \\
\left(\mathrm{mm}^{2}\right)\end{array}$ & $\begin{array}{l}\text { Section size } \\
(\mathrm{mm} \times \mathrm{mm})\end{array}$ & $\begin{array}{c}\text { Section area } \\
\left(\mathrm{mm}^{2}\right)\end{array}$ \\
\hline Tower leg & $\mathrm{L} 90 \times 7$ & 1230 & $\mathrm{~L} 40 \times 4$ & 309 \\
\hline $\begin{array}{l}\text { Horizontal } \\
\text { diaphragm }\end{array}$ & $\mathrm{L} 56 \times 4$ & 439 & $\mathrm{~L} 28 \times 2$ & 112 \\
\hline \multirow{3}{*}{ Bracing } & $\mathrm{L} 50 \times 4$ & 390 & $\mathrm{~L} 25 \times 2$ & 100 \\
\hline & $\mathrm{L} 45 \times 4$ & 349 & $\mathrm{~L} 23 \times 2$ & 92 \\
\hline & $\mathrm{L} 40 \times 3$ & 236 & $\mathrm{~L} 20 \times 1.5$ & 60 \\
\hline $\begin{array}{l}\text { Auxiliary } \\
\text { member }\end{array}$ & $\mathrm{L} 40 \times 3$ & 236 & $\mathrm{~L} 20 \times 1.5$ & 60 \\
\hline
\end{tabular}

Note: The angles of L40x4 and L90 $\times 7$ are hot rolled, others are cold worked

Table 2. The measured yield strength of the angles (MPa)

\begin{tabular}{c|c|c}
\hline Hot rolled angle L40 $\times 4$ & 2 mm-thick cold worked angle & 1.5 mm-thick cold worked angle \\
\hline 323.3 & 309.2 & 313.1 \\
\hline
\end{tabular}

Table 3. Normal working loading conditions for the prototype whole tower

\begin{tabular}{c|c|c|c|c|c|c}
\hline \multicolumn{3}{c|}{ Horizontal load (N) } & \multicolumn{3}{c}{ Vertical load (N) } \\
\hline Wire & $\begin{array}{c}\text { Shield wires, } \\
\text { conductors } \\
\text { and } \\
\text { insulators }\end{array}$ & Earth wire & Wire & $\begin{array}{c}\text { Shield wires, } \\
\text { conductors } \\
\text { and } \\
\text { insulators }\end{array}$ & Earth wire & $\begin{array}{c}\text { Self-weight } \\
\text { of the tower }\end{array}$ \\
\hline 0 & 0 & 0 & 6964 & 1182 & 5977 & 27979 \\
\hline
\end{tabular}

Note: Normal working condition assumes a temperature of $15^{\circ} \mathrm{C}$, no wind load and ice covering, only the self-weight of the tower, is considered. 


\section{List of figures}

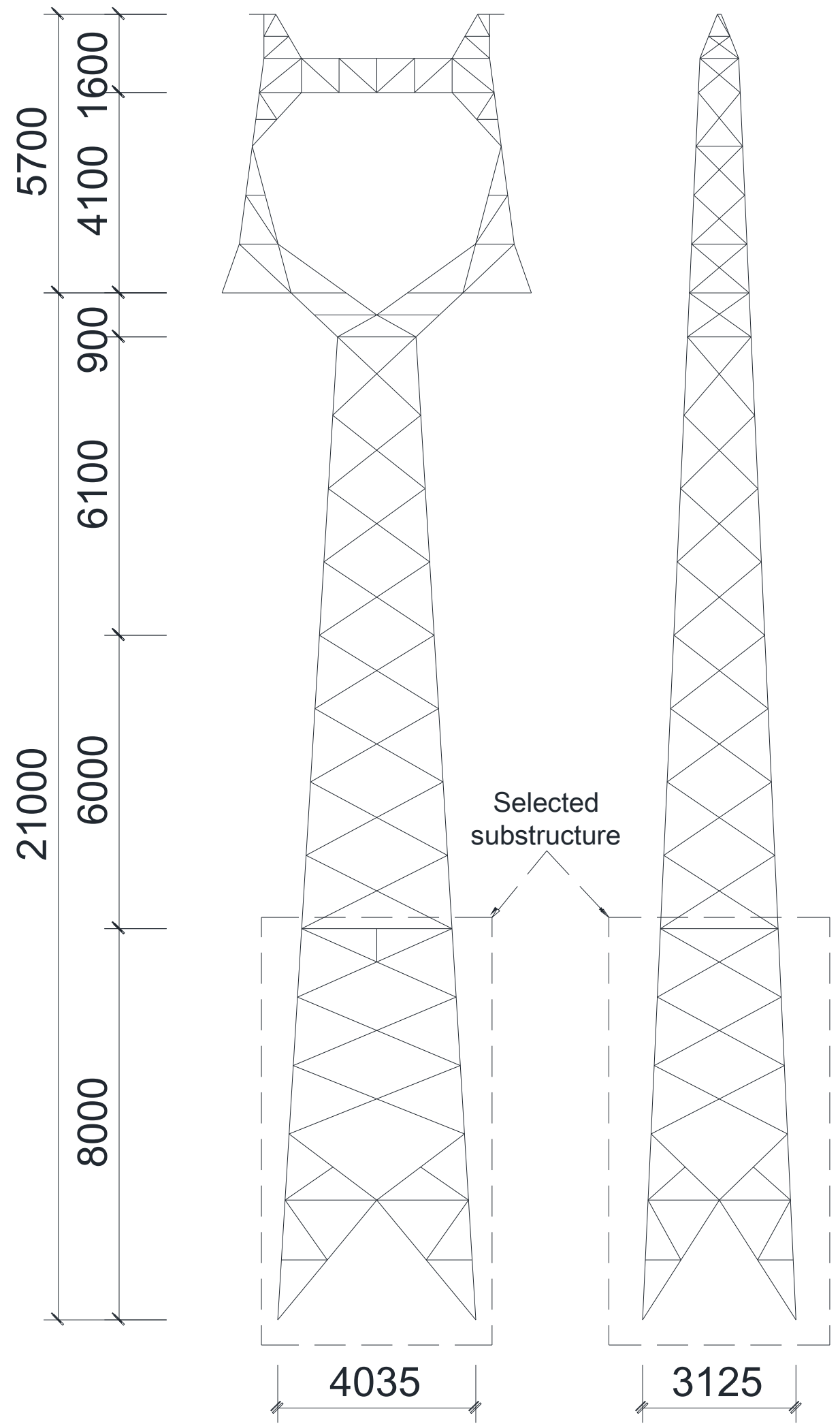

Fig. 1 A prototype of $110 \mathrm{kV}$ single circuit transmission tower (all dimensions in $\mathrm{mm}$ ). 


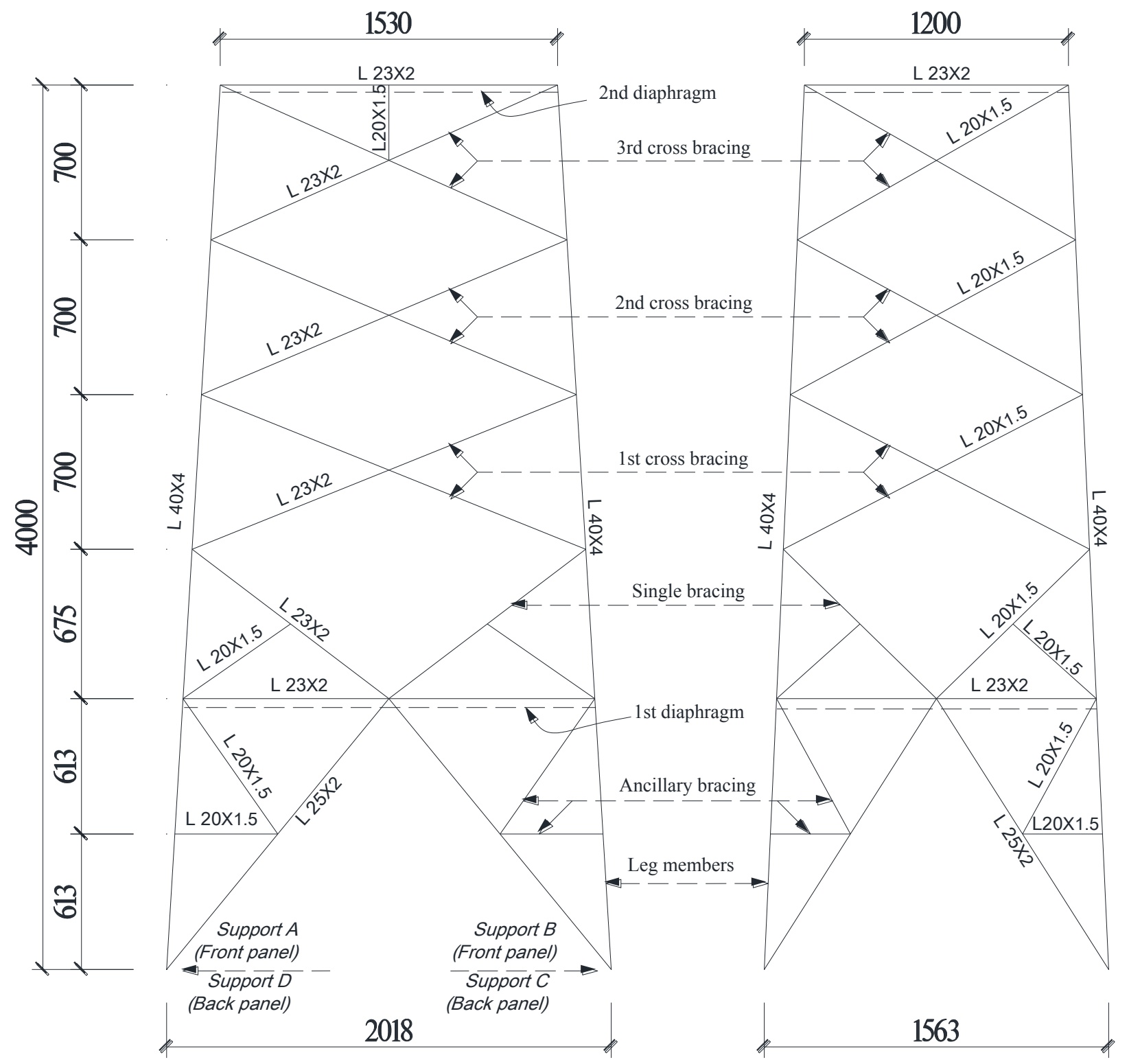

Fig. 2 The half-scaled test tower model (all dimensions in $\mathrm{mm}$ ). 


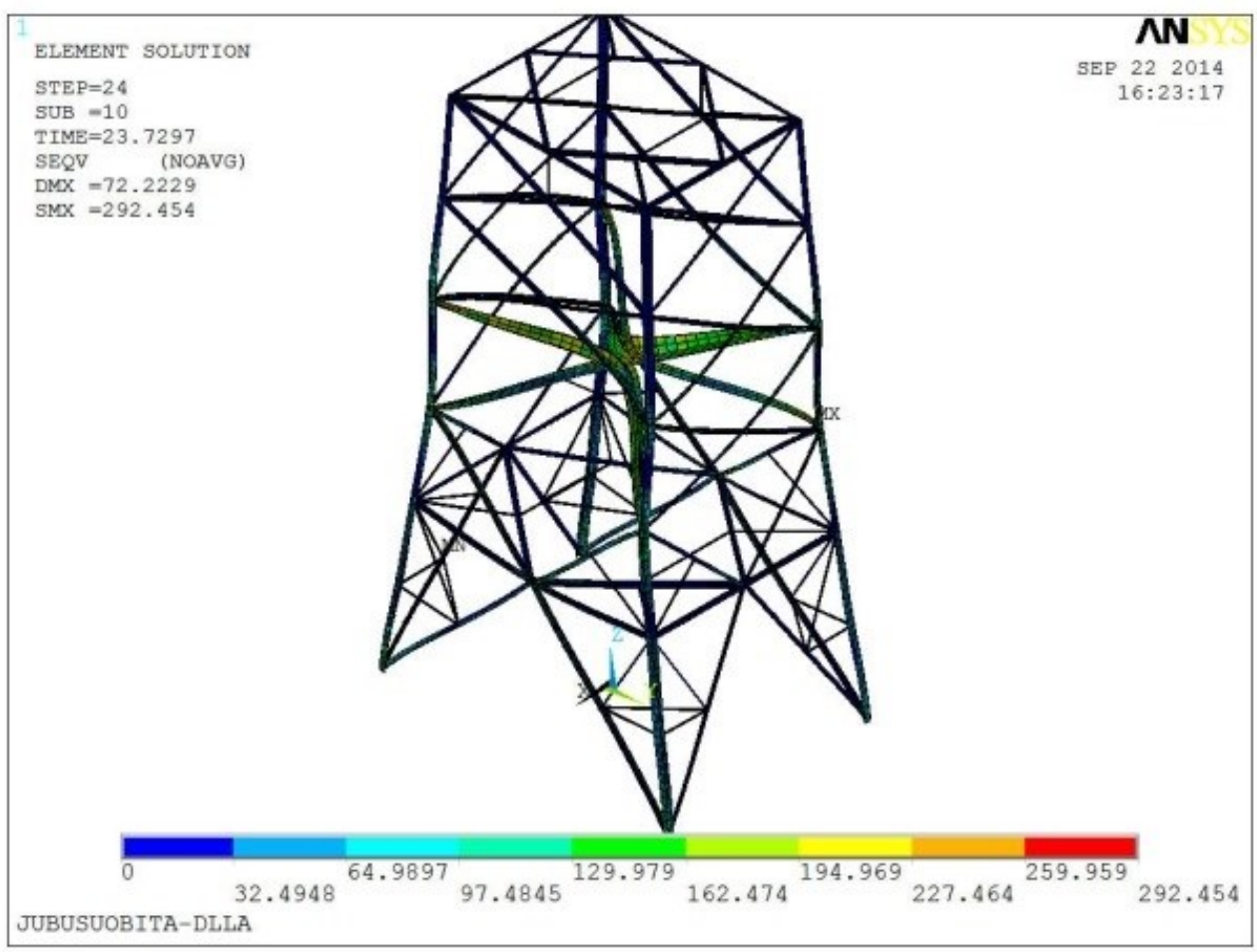

(a) The scaled test tower model

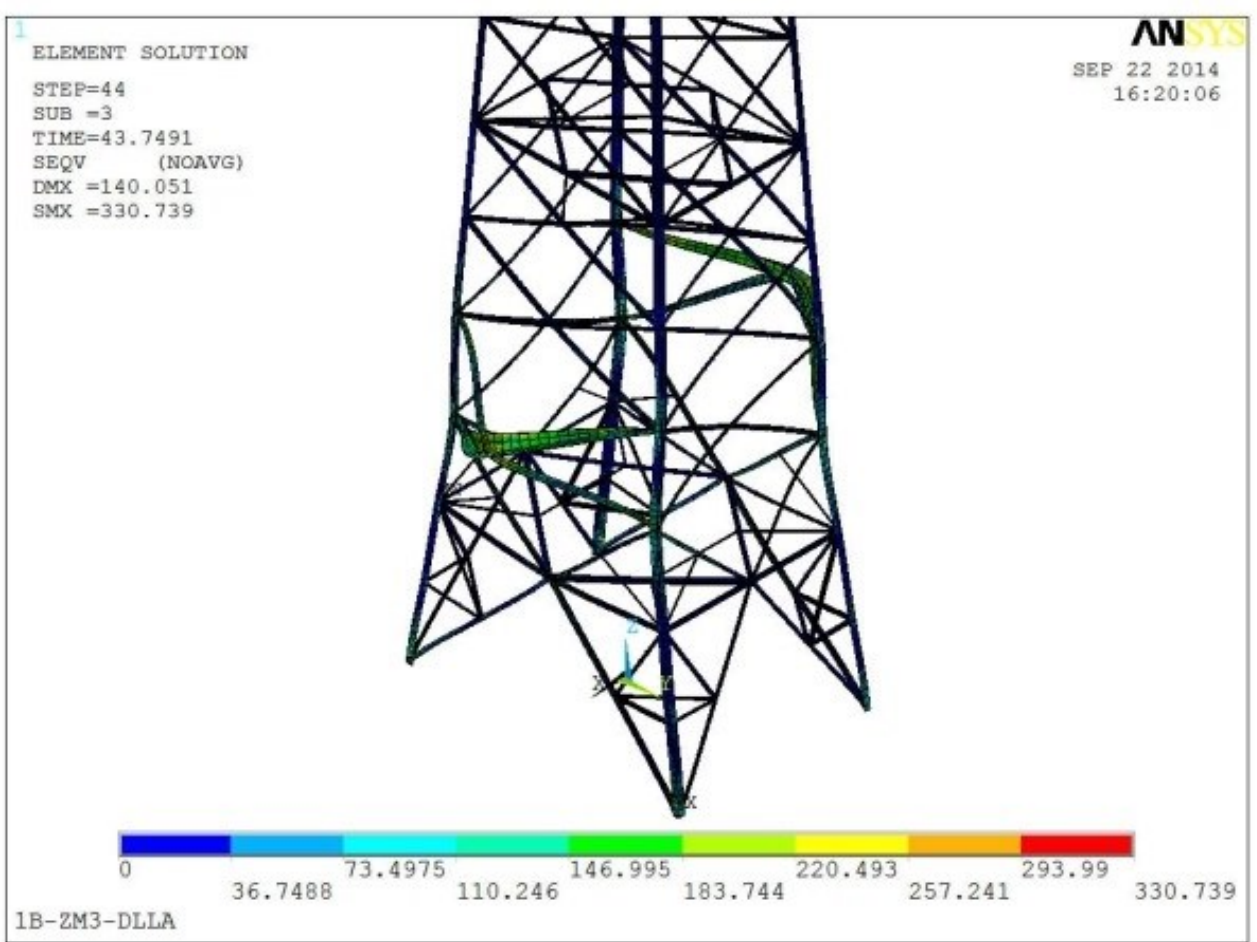

(b) The original whole tower

Fig. 3 The comparison of predicted deformed shapes between the scaled test tower model and the original whole tower (enlarged 10 times). 


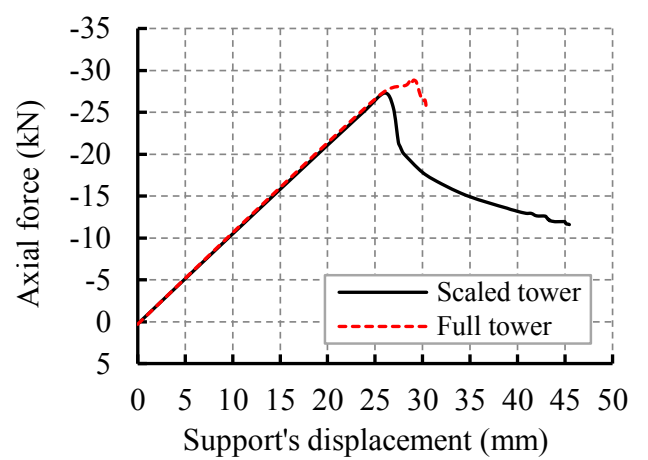

(a) The axial force of $1^{\text {st }}$ cross bracing member

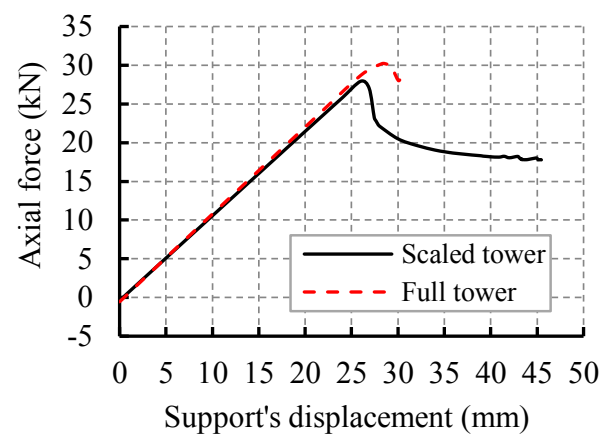

(c) The axial force of tower leg member

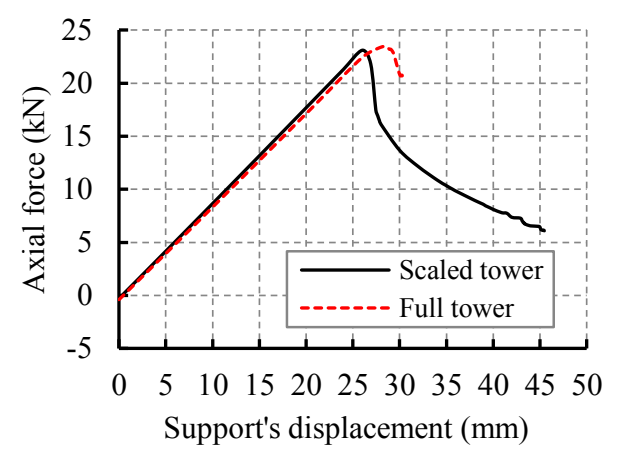

(b) The axial force of $2^{\text {nd }}$ cross bracing member

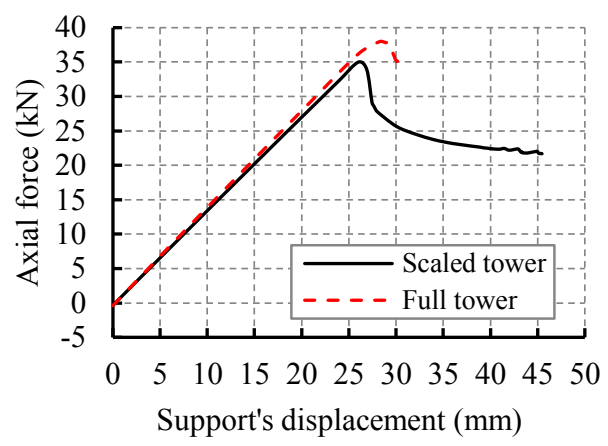

(d) The axial force of single bracing member

Fig. 4 The comparisons of the axial forces of some key members for both FE analyses.

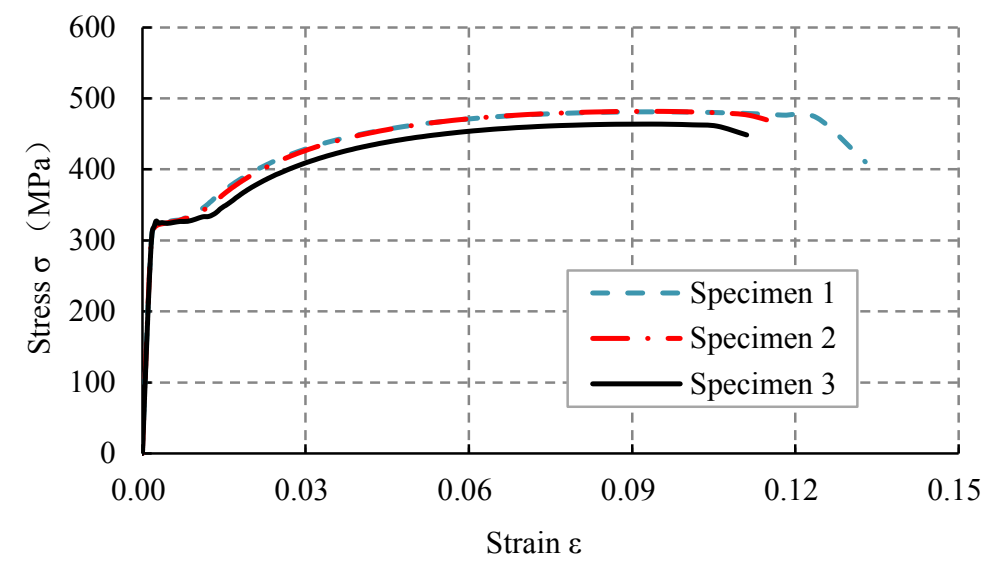

Fig. 5 Tested stress-strain curve of L40 $\times 4$ angle. 


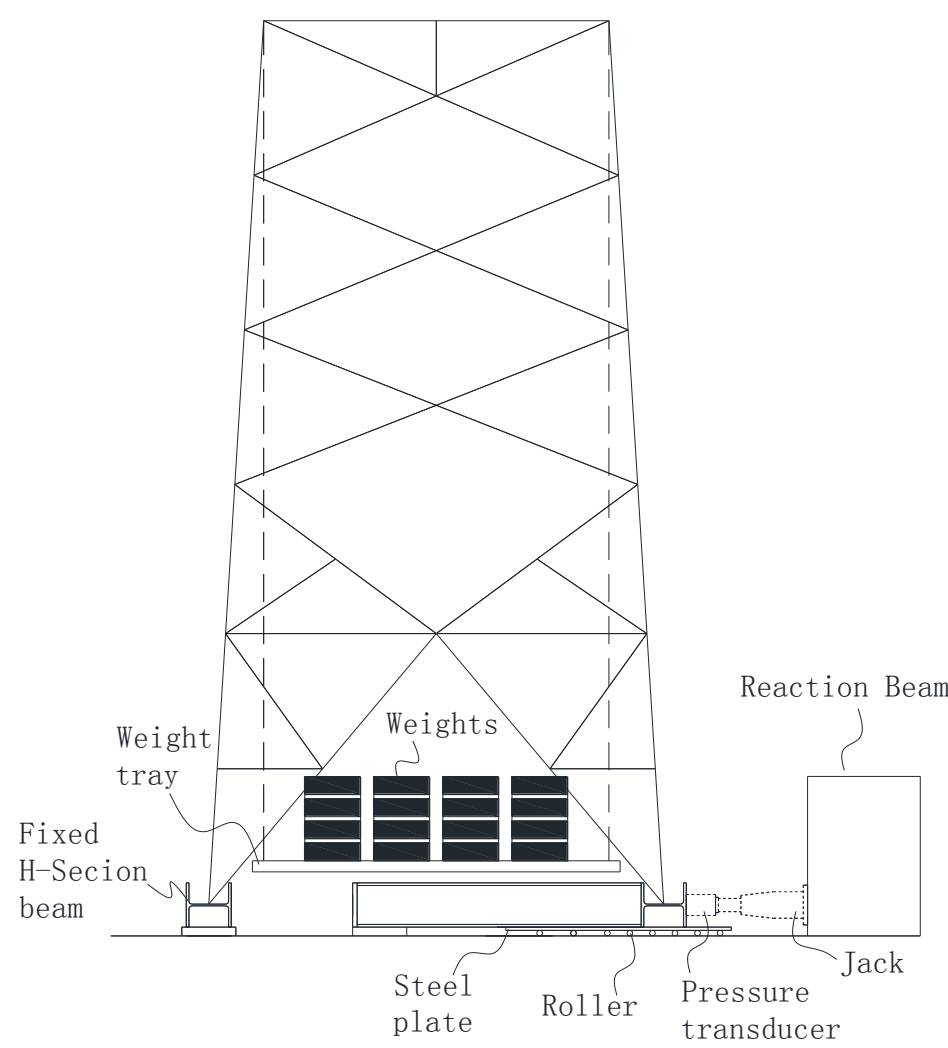

(a) Front Elevation

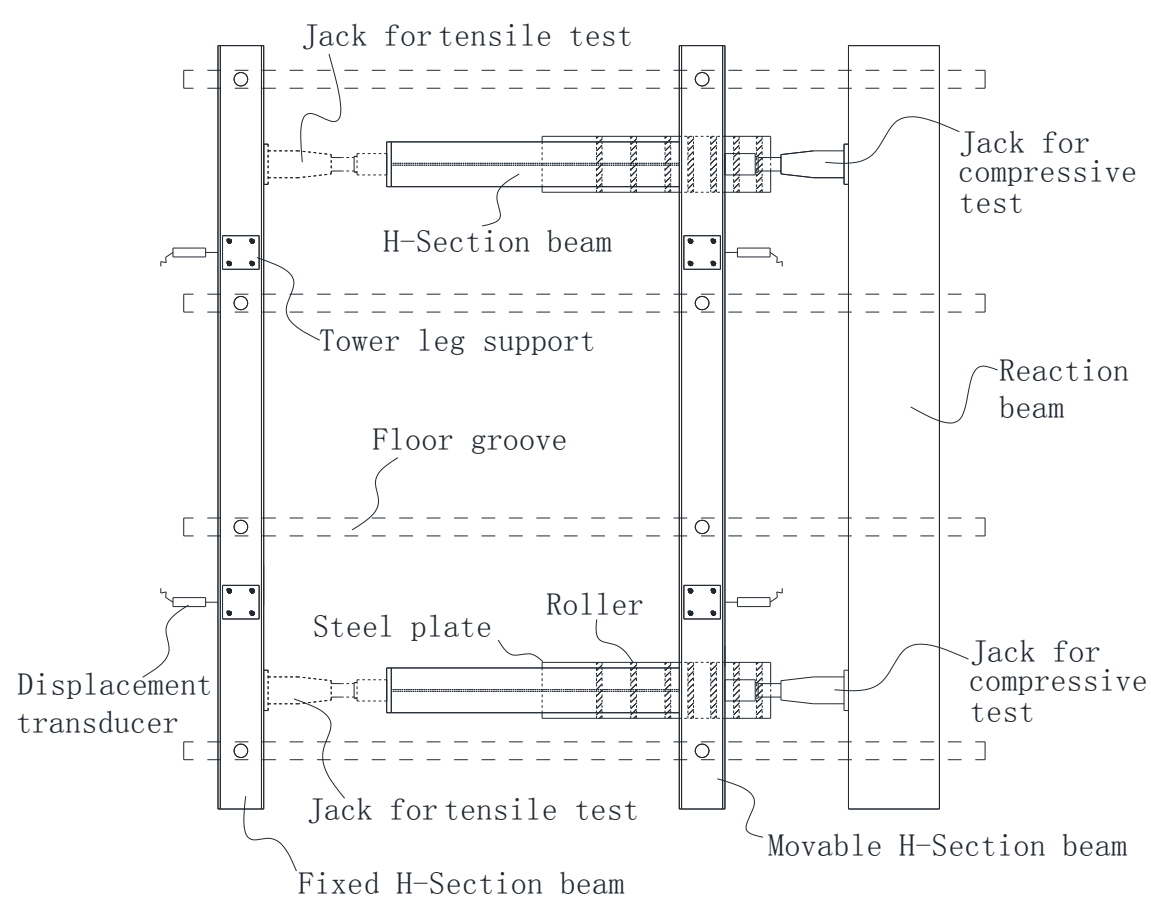

(b) Plan View

Fig. 6 The arrangements of the loading and horizontal support's movements along the direction perpendicular to the line. 


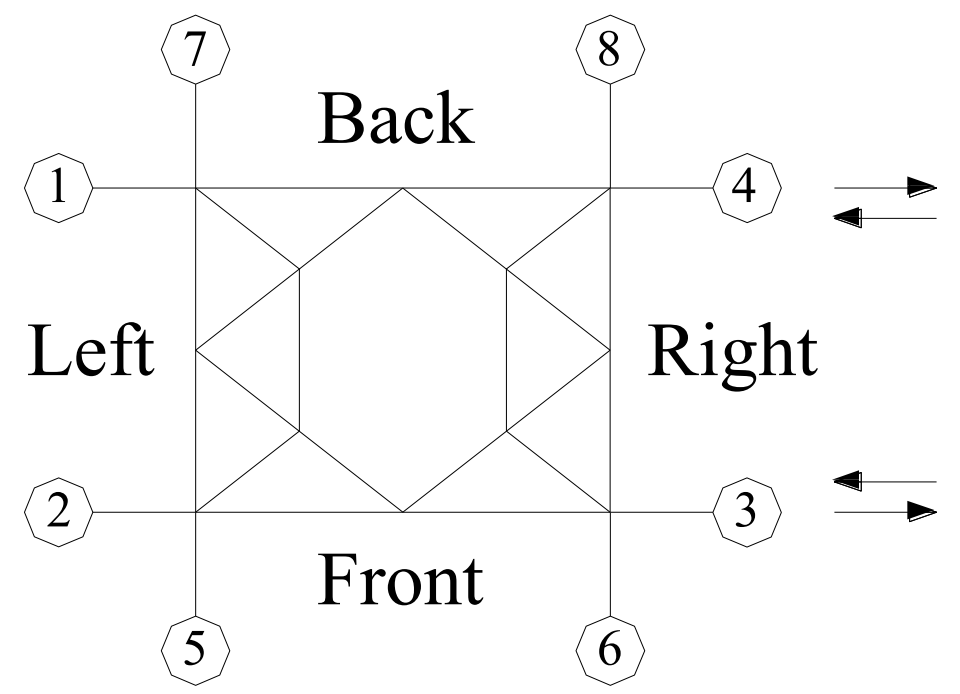

Fig. 7 Arrangement of 8 guyed displacement meters at 4 top corners of the scaled test tower model.
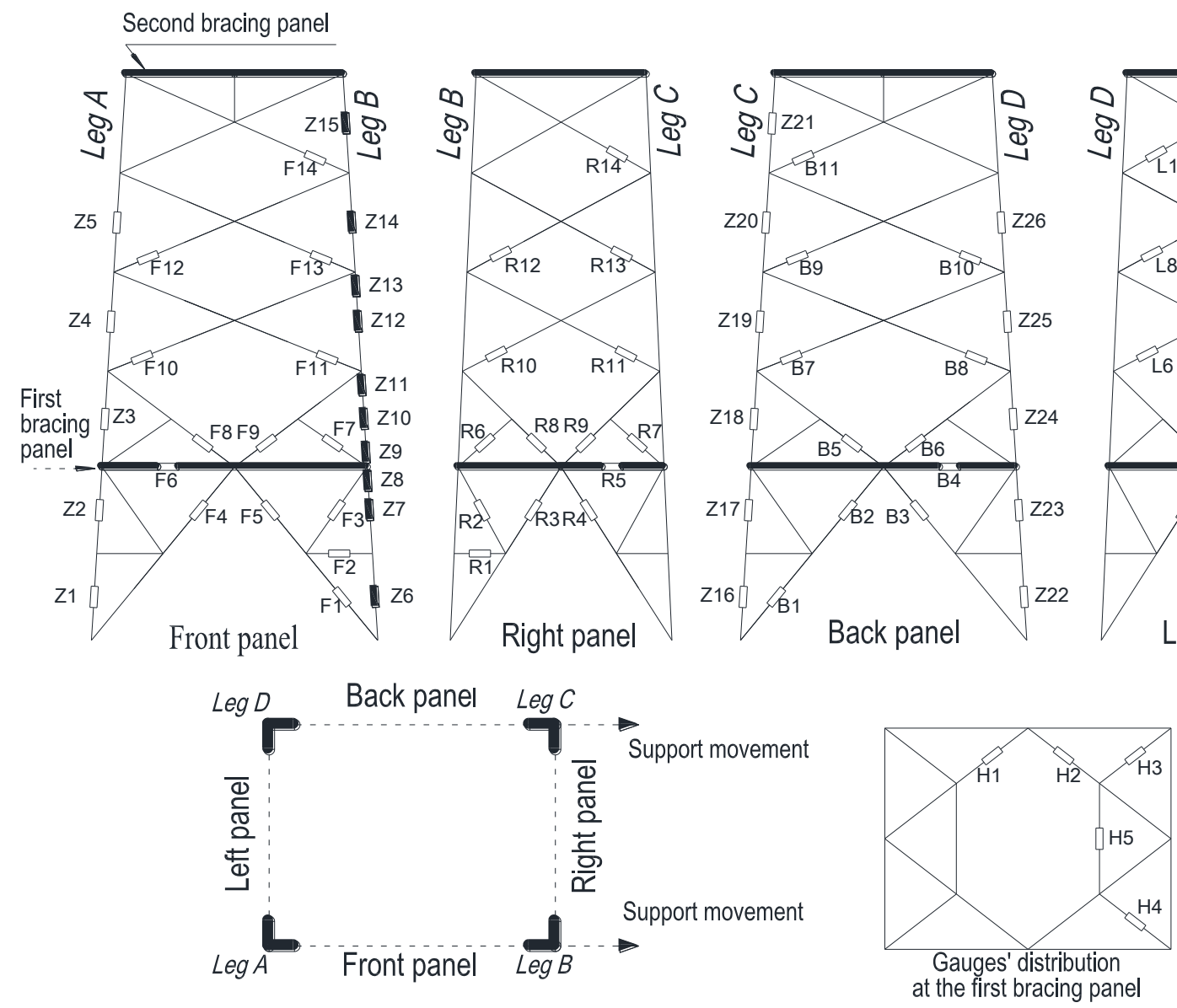

Fig. 8 The arrangement of the strain gauges in the truss members of the scaled test tower model. 


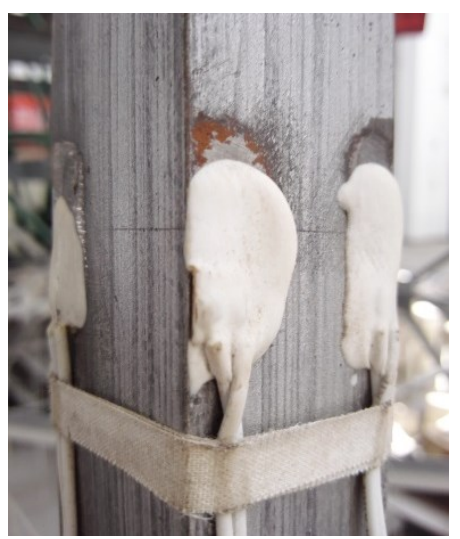

(a) Strain gauges fixed on the tower's legs

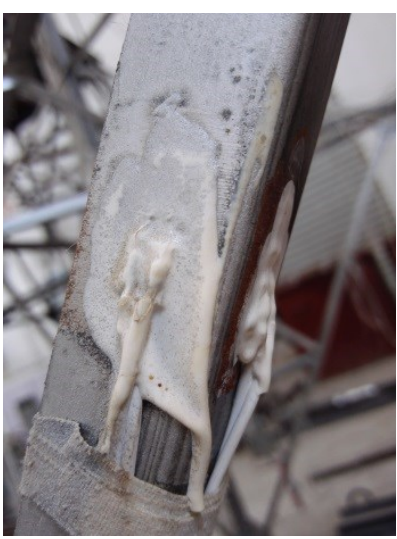

(b) Strain gauges fixed on other truss members

Fig. 9 Details of the strain gauges attached on the structural members.

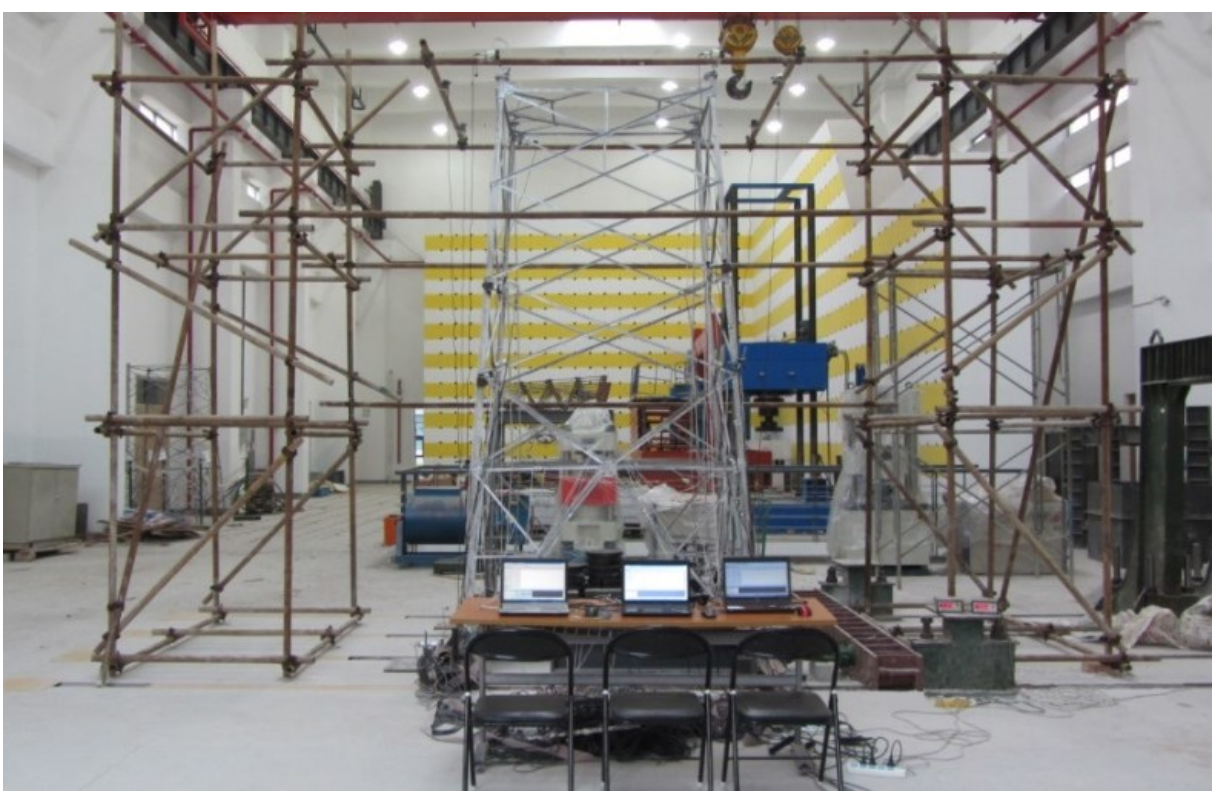

Fig. 10 Panorama view of the test.

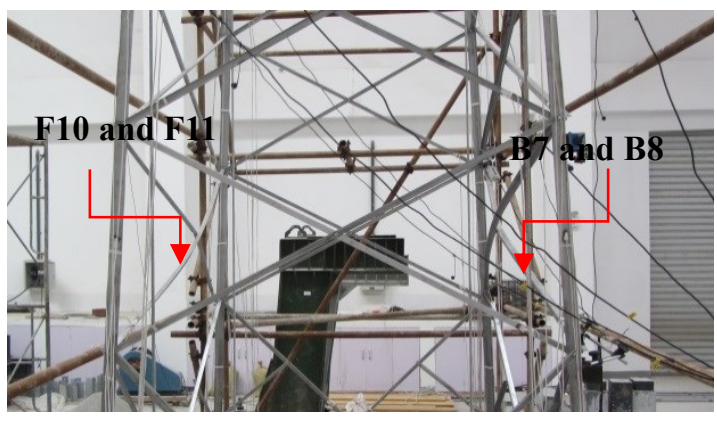

(a) Deformations of members F10, F11, B7 and B8

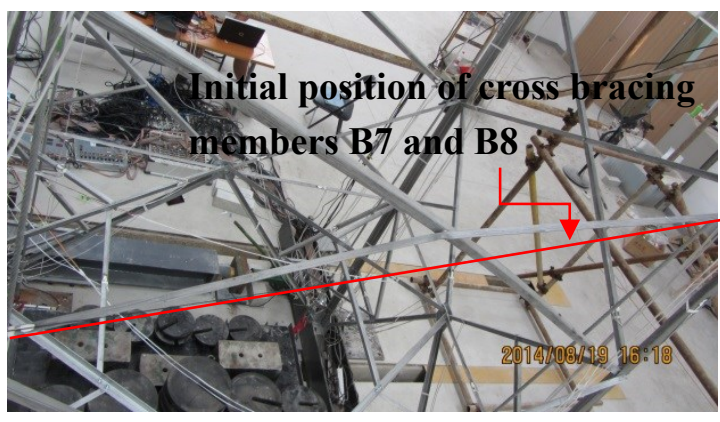

(b) Deformations of members B7 and B8

Fig. 11 The deformations of the first cross bracing members. 


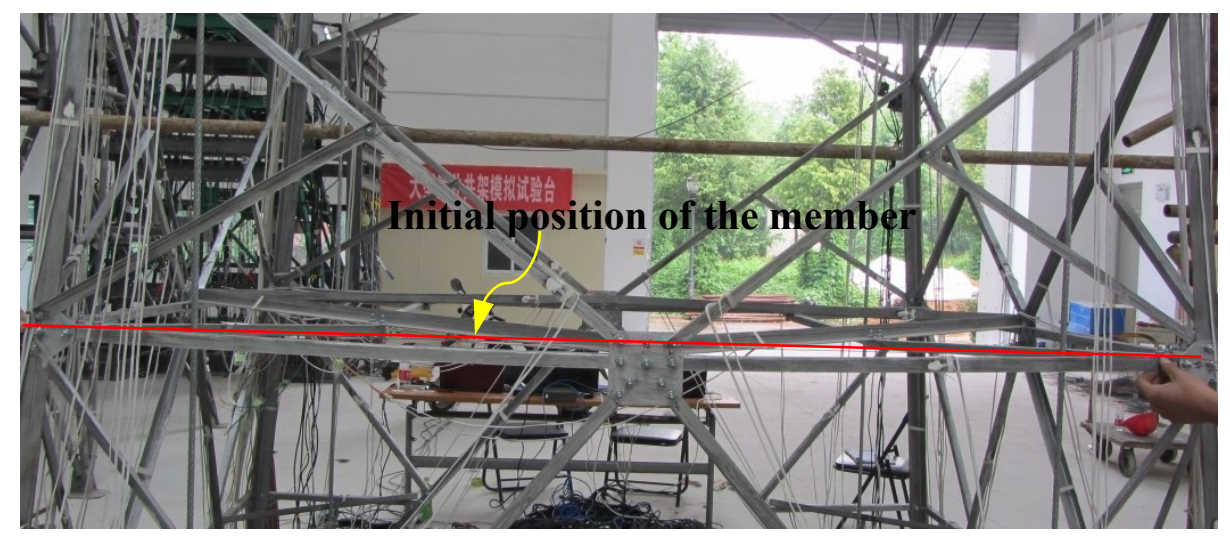

Fig. 12 The deformations of the first diaphragm members.

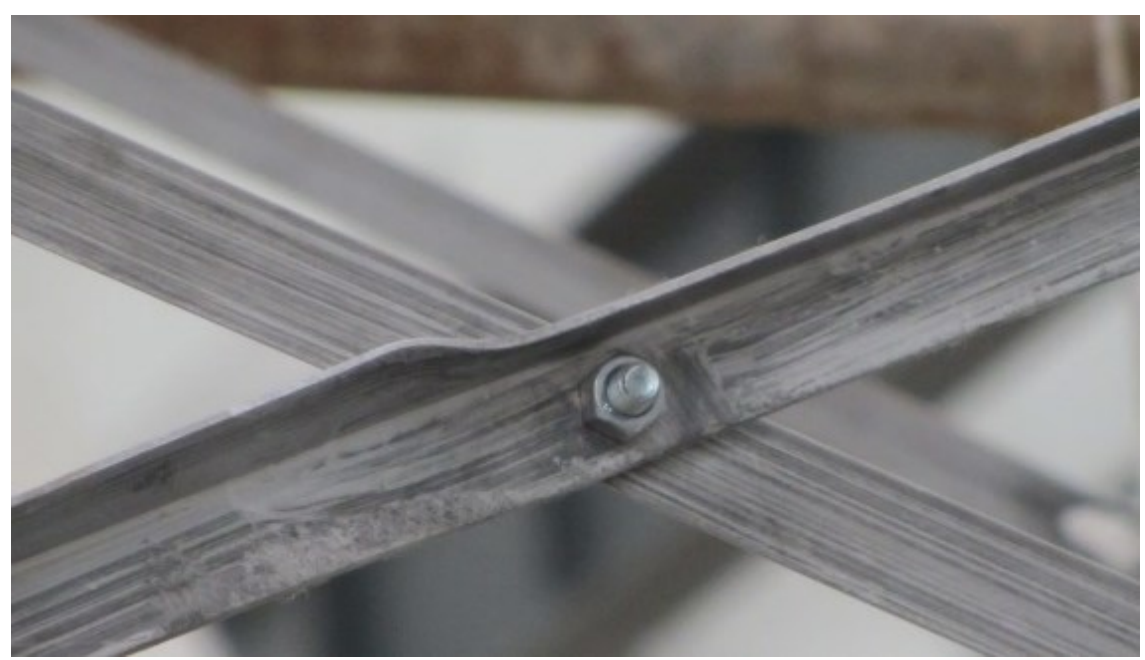

Fig. 13 Angle buckling near the center bolted connection node of the first cross bracing members. 


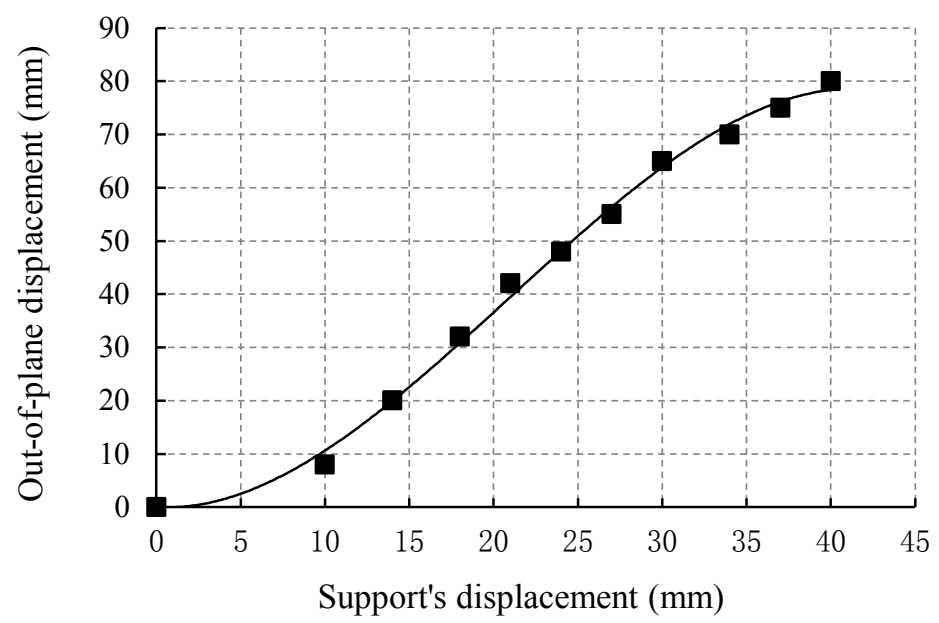

Fig. 14 The outward out-of-plane displacement at the first cross bracing joint (F10-F11) against the support's displacement.

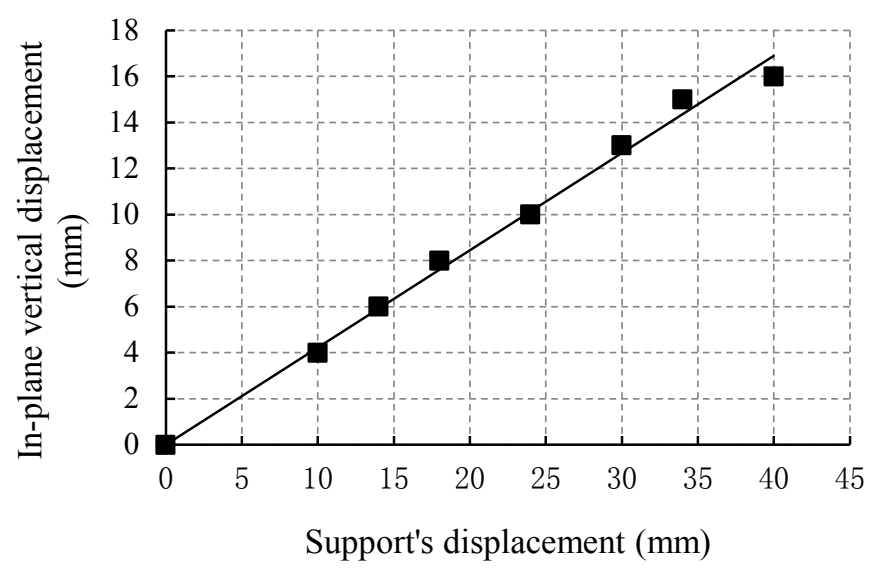

Fig. 15 The in-plane vertical displacement at the midpoint of the horizontal diaphragm member F6 against the support's displacement. 


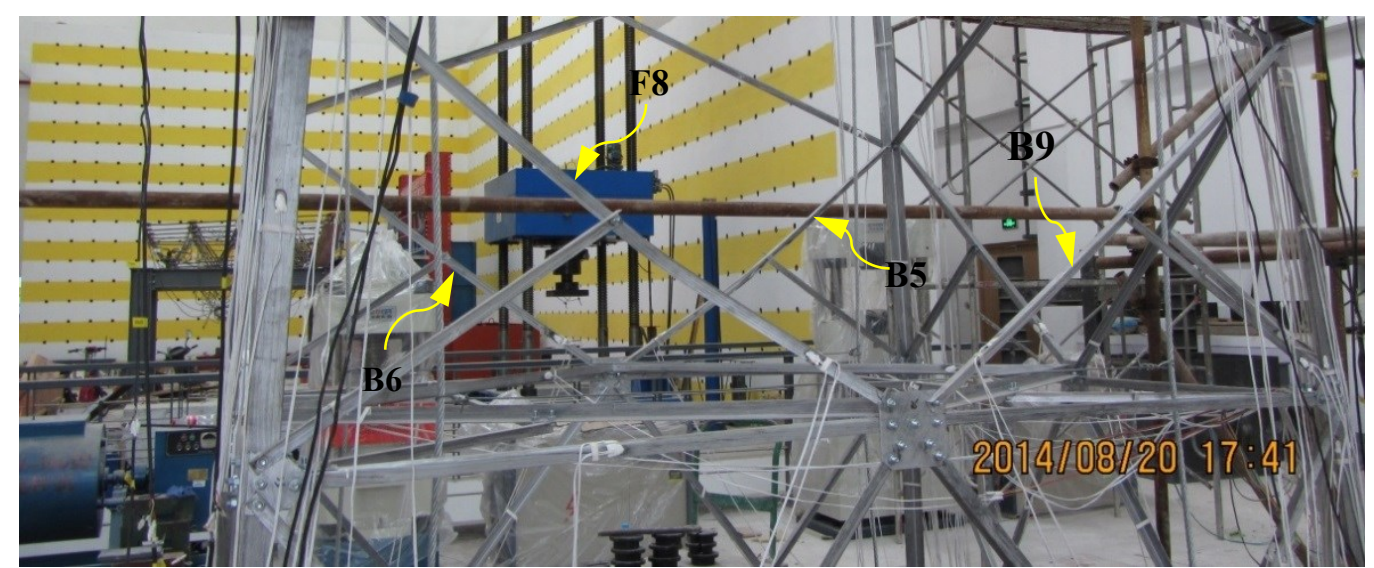

(a) Members F8, B5, B6, B9

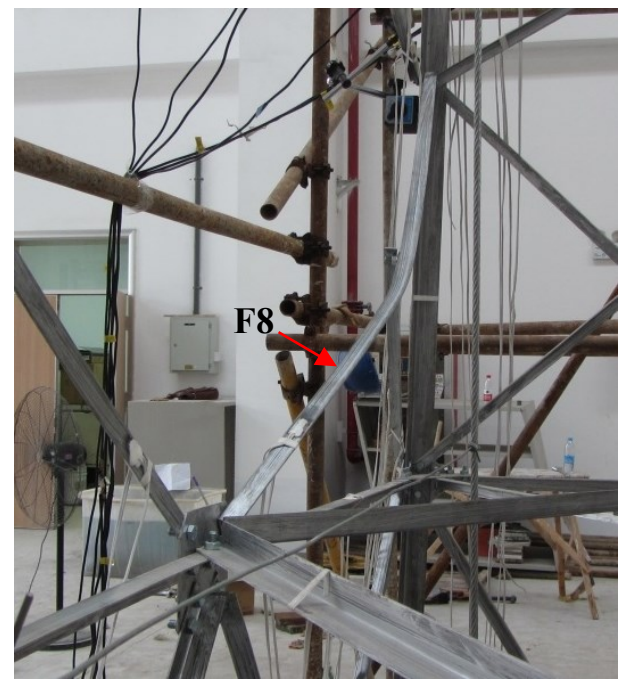

(b) Member F8

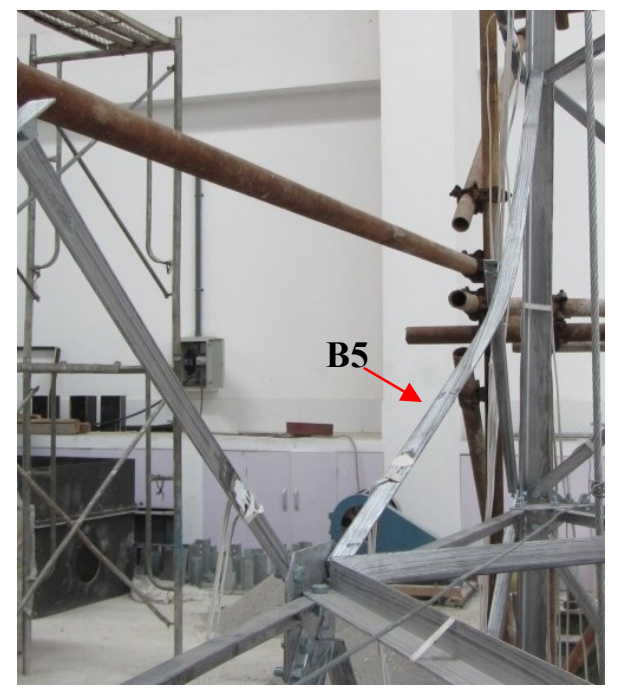

(c) Member B5

Fig. 16 The deformations of some key truss members.

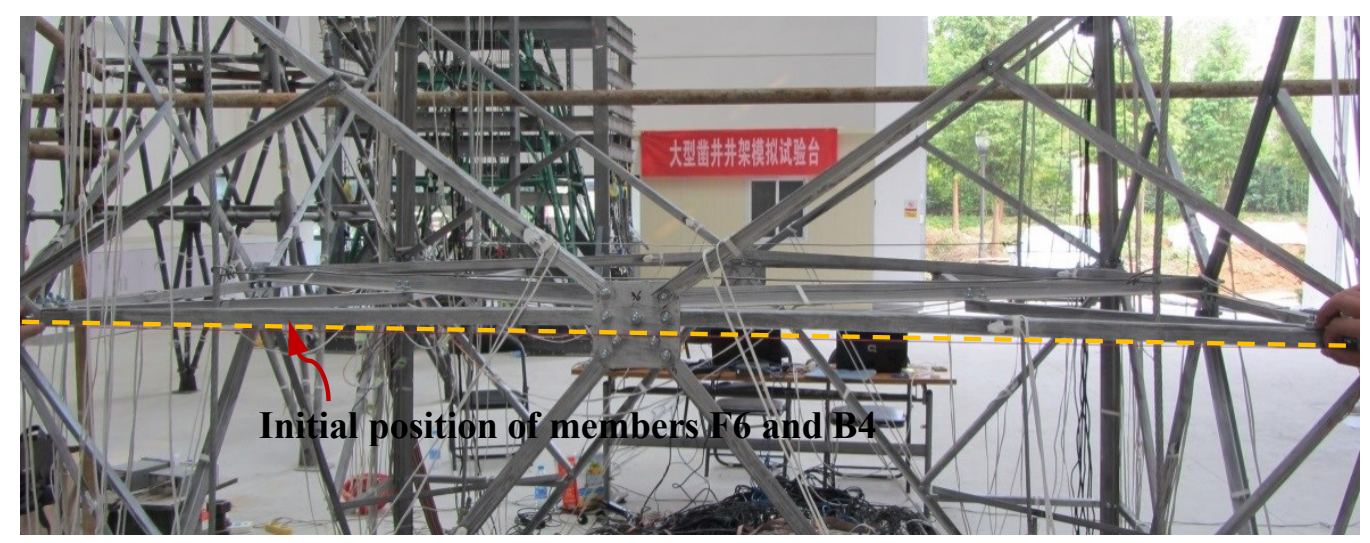

Fig. 17 The deformations of the first horizontal diaphragm members F6 and B4. 


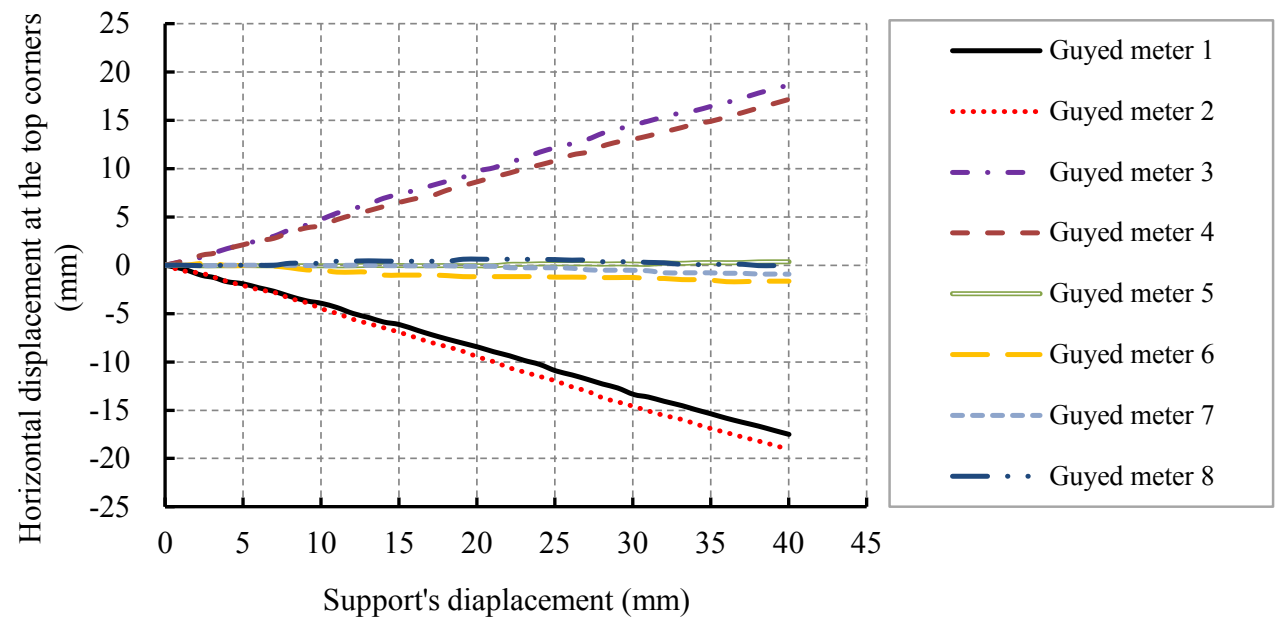

Fig. 18 The horizontal displacements at the top corners of the scaled test tower model versus the tensile support's displacements (in Fig. 7 for the positions of the guyed meters).

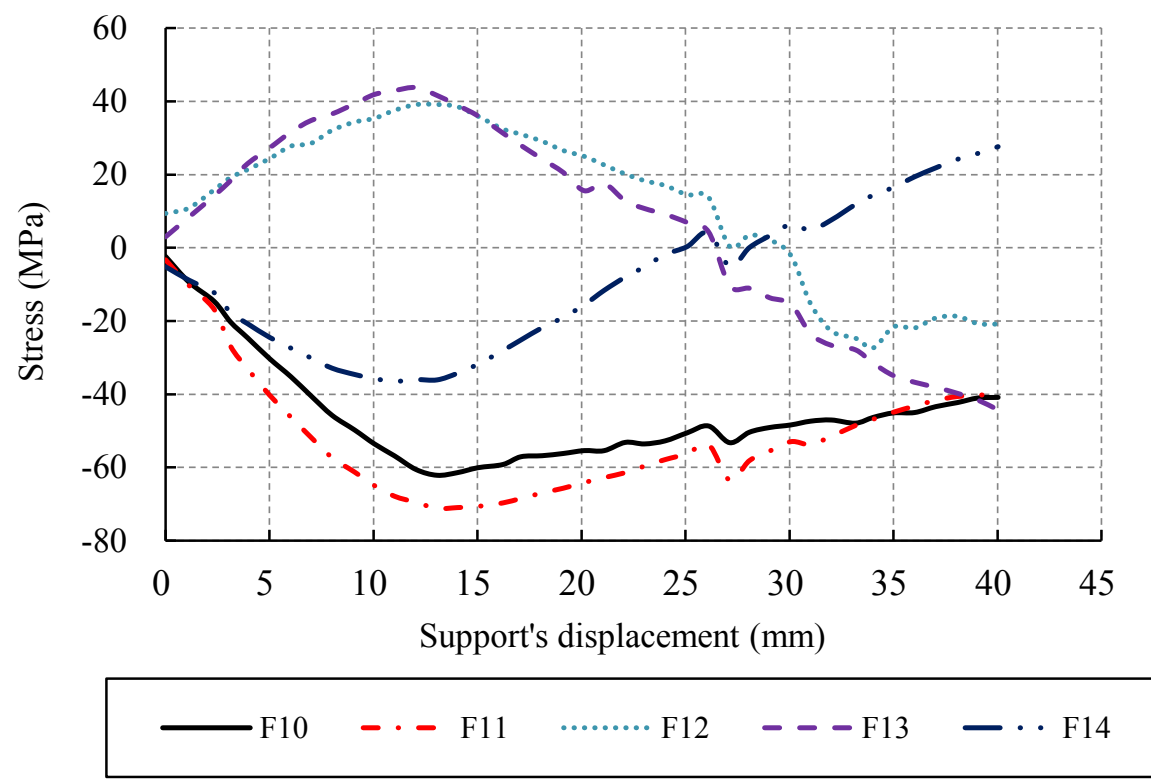

Fig. 19 The stresses of the cross bracing members versus the tensile support's displacements. 


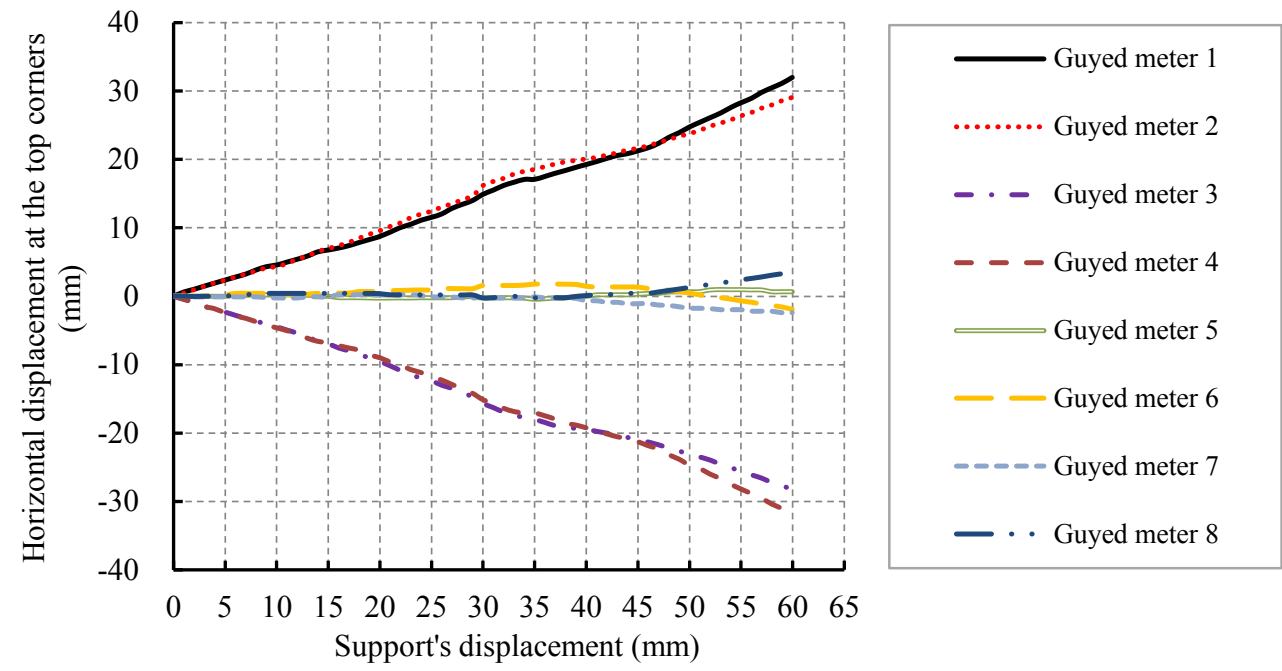

Fig. 20 The horizontal displacements at the top corners of the scaled test tower model versus the compressive support's displacements (in Fig. 7 for the positions of the guyed meters).
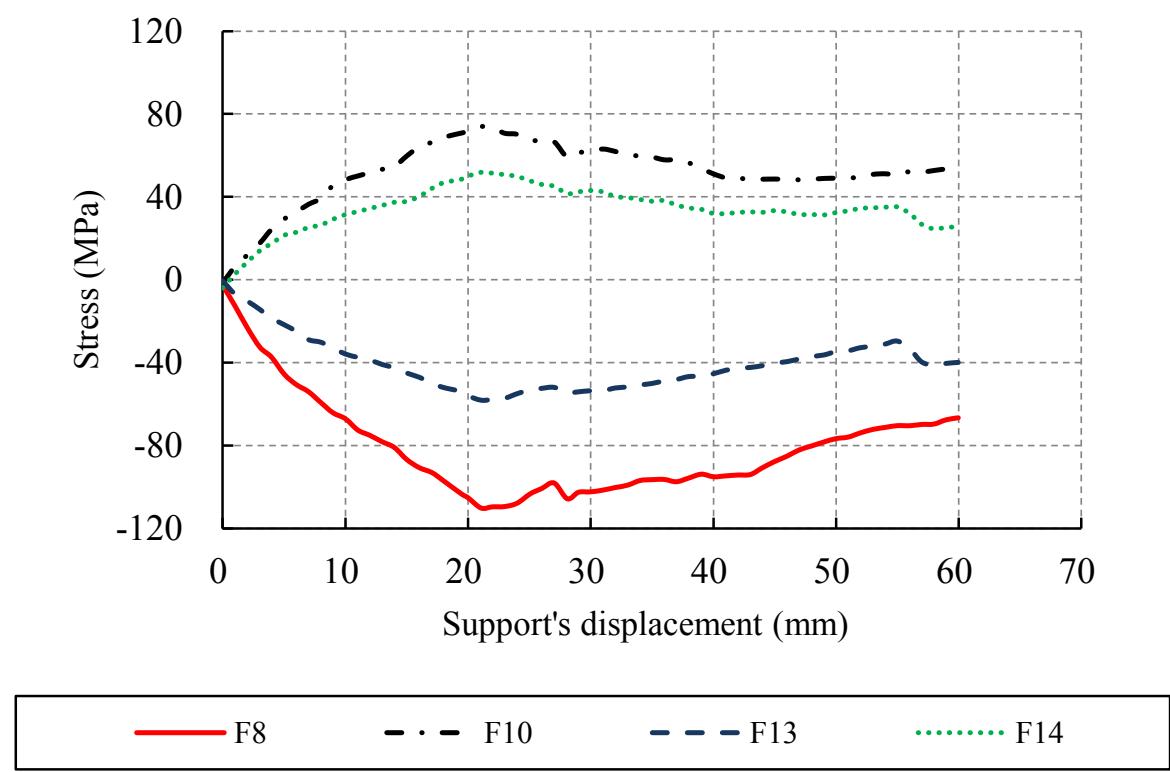

Fig. 21 The stresses of the cross bracing members versus the compressive support's displacements. 


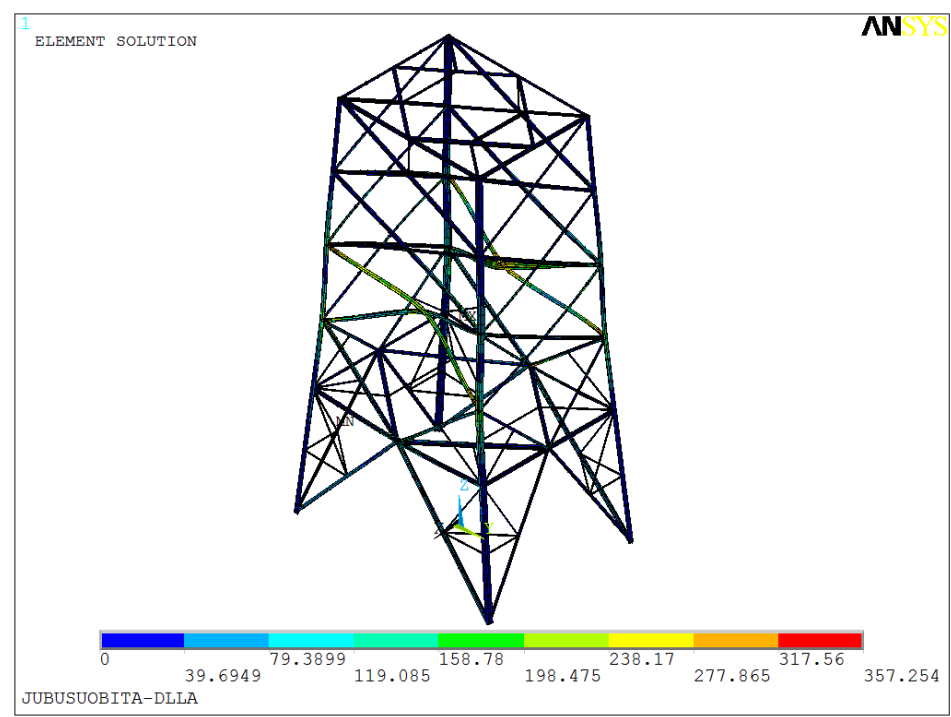

Fig. 22 The predicted deformations of the scaled test tower model (tensile test).

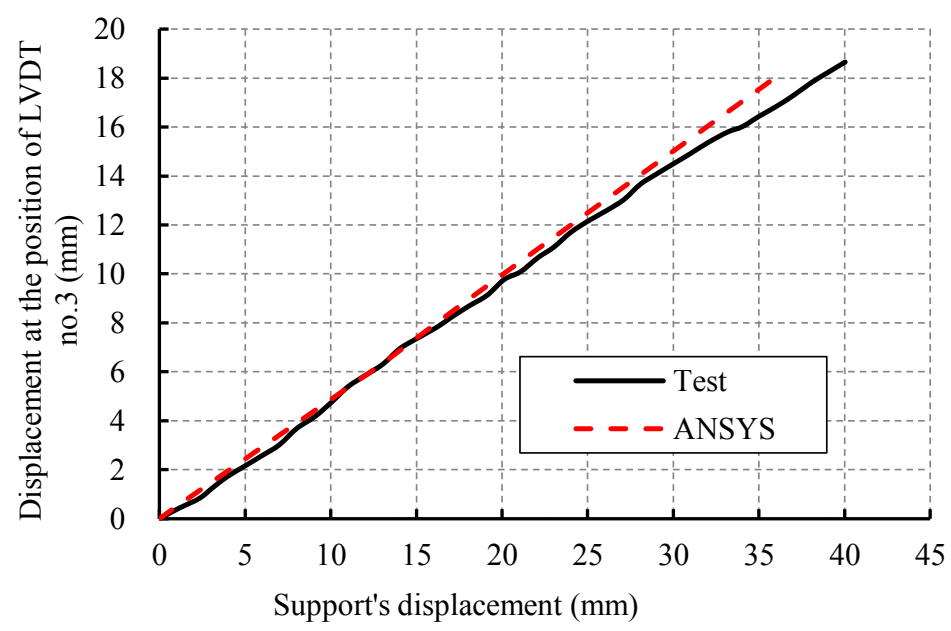

Fig. 23 The comparison of the predicted and measured displacements at the position of LVDT no. 3 (tensile test). 


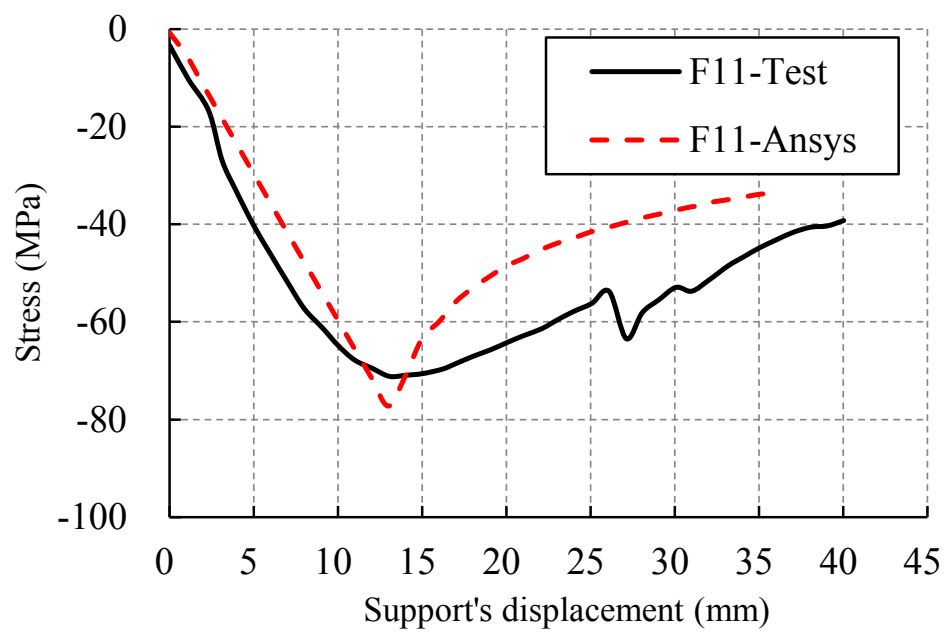

Fig. 24 The comparison of the predicted and measured stresses within the first cross bracing member F11 (tensile test).

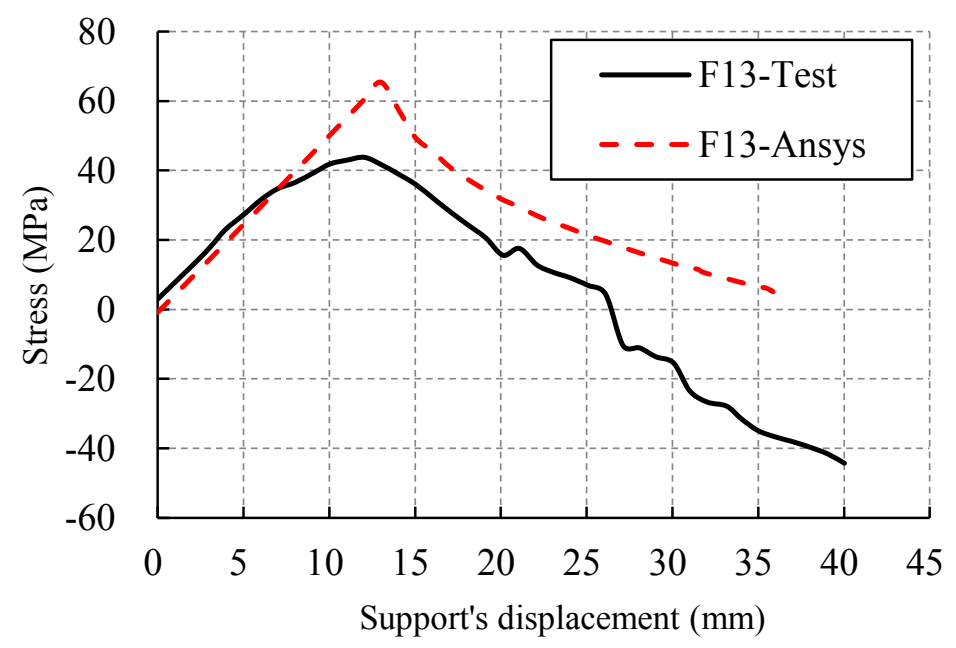

Fig. 25 The comparison of the predicted and measured stresses within the second cross bracing member F13 (tensile test). 


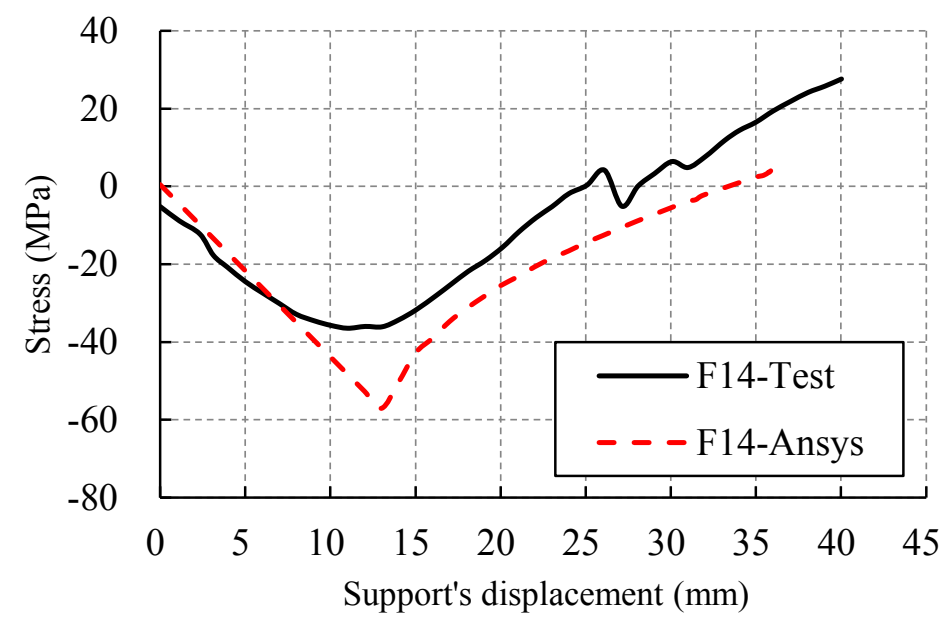

Fig. 26 The comparison of the predicted and measured stresses within the third cross bracing member F14 (tensile test).

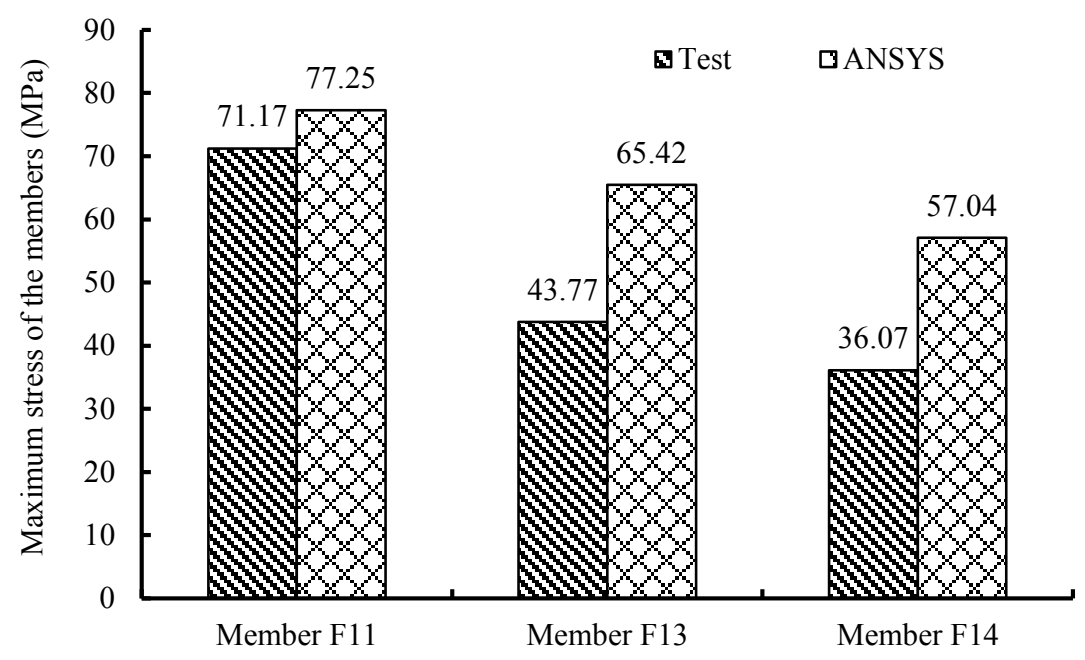

Fig. 27 The comparison of the predicted and measured maximum stresses within the cross bracing members (tensile test). 


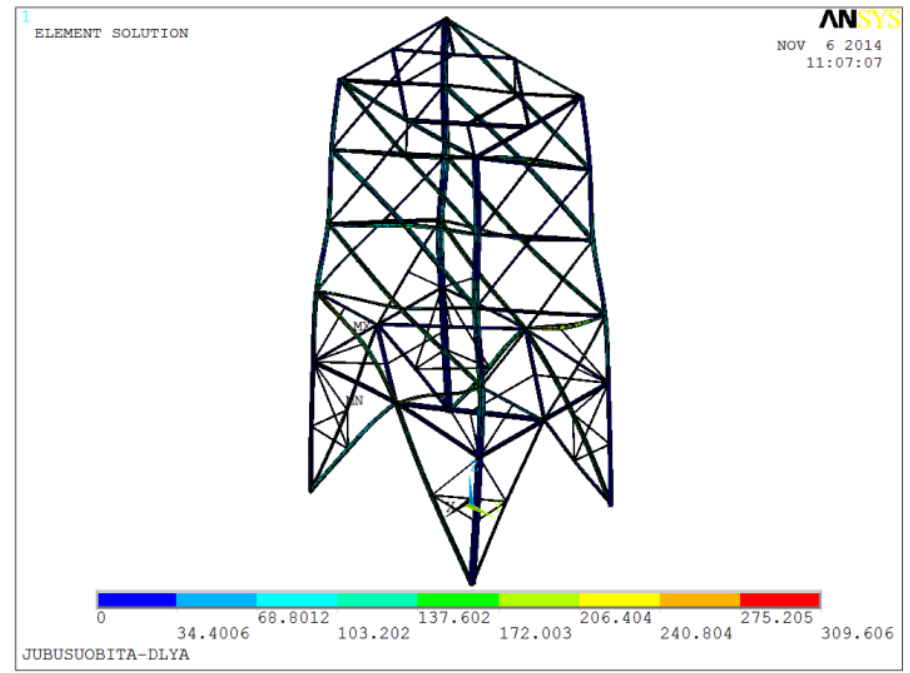

Fig. 28 The predicted deformations of the scaled test tower model (compressive test).

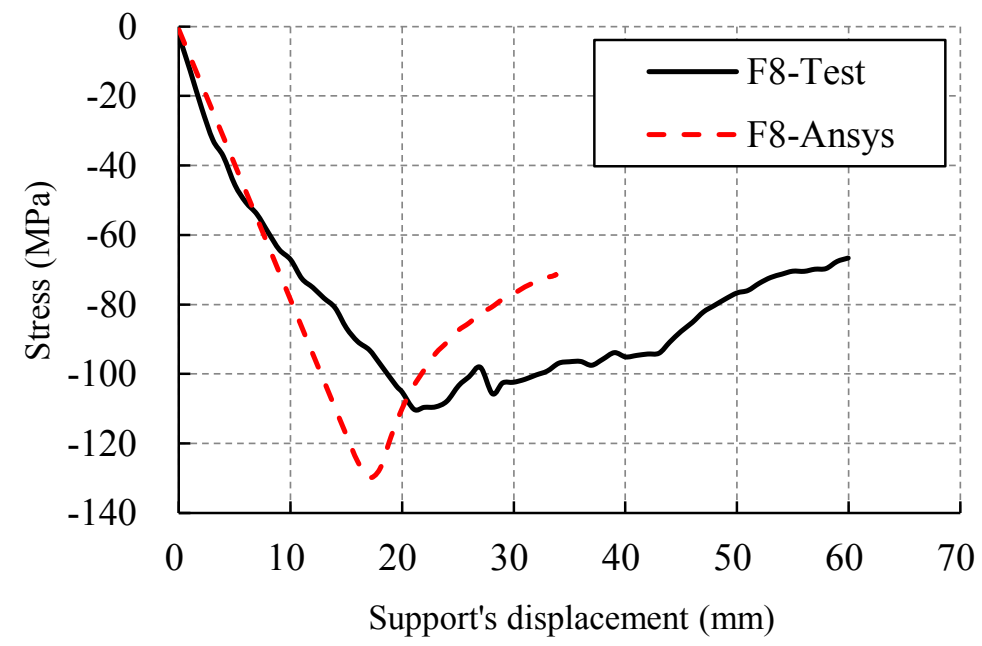

Fig. 29 The comparison of the predicted and measured stresses within the bracing member F8 (compressive test). 


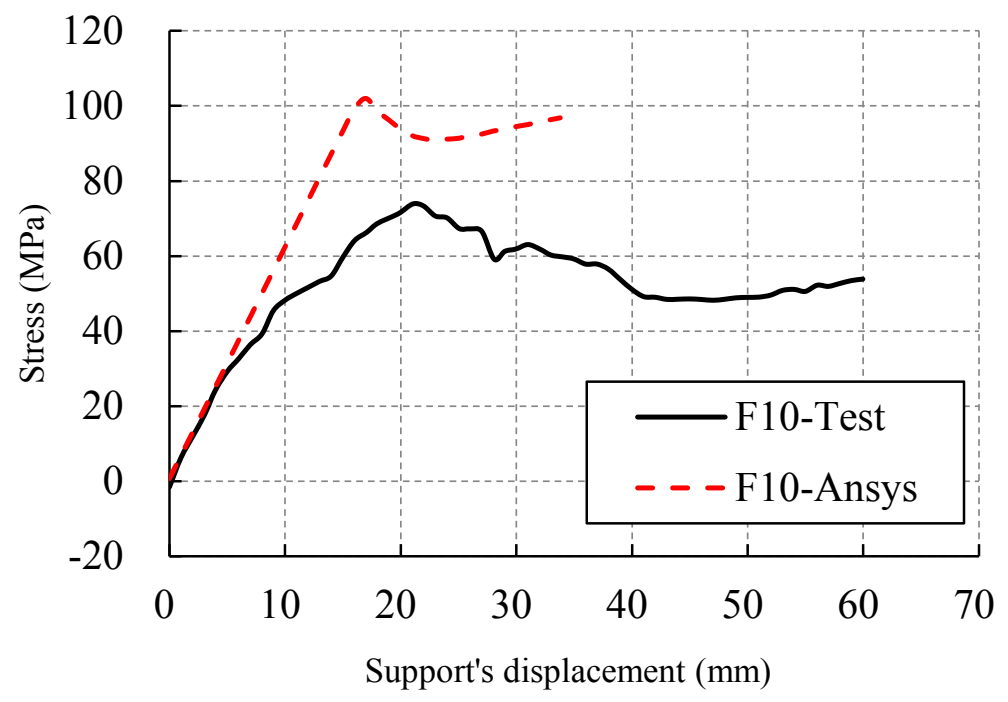

Fig. 30 The comparison of the predicted and measured stresses within the bracing member F10 (compressive test).

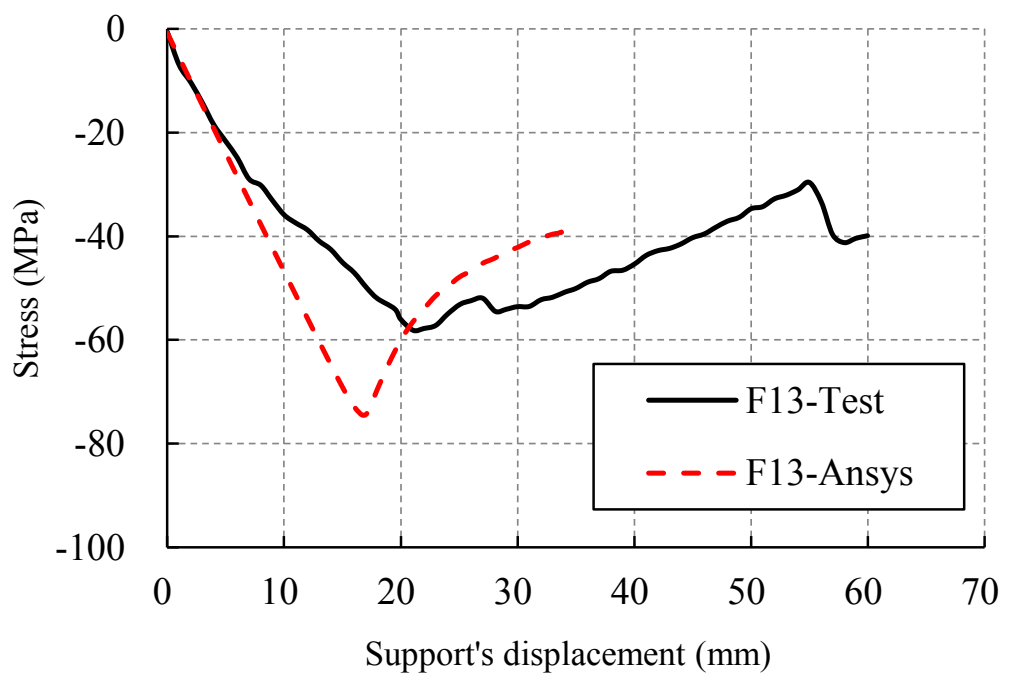

Fig. 31 The comparison of the predicted and measured stresses within the bracing member F13 (compressive test). 


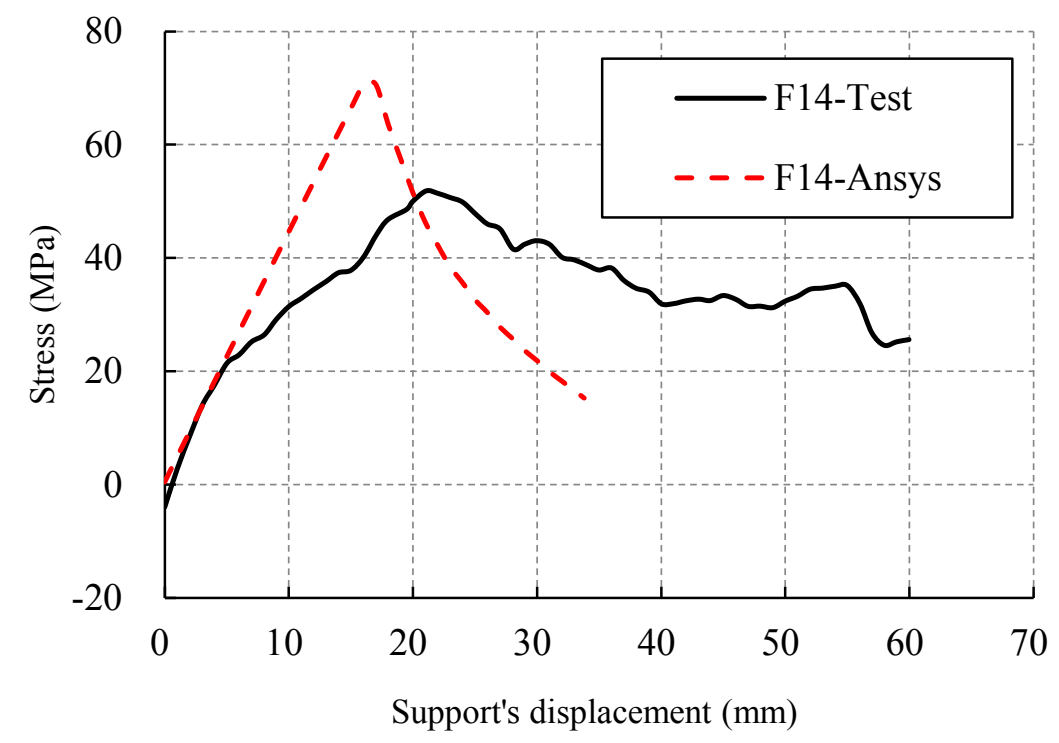

Fig. 32 The comparison of the predicted and measured stresses within the bracing member F14 (compressive test).

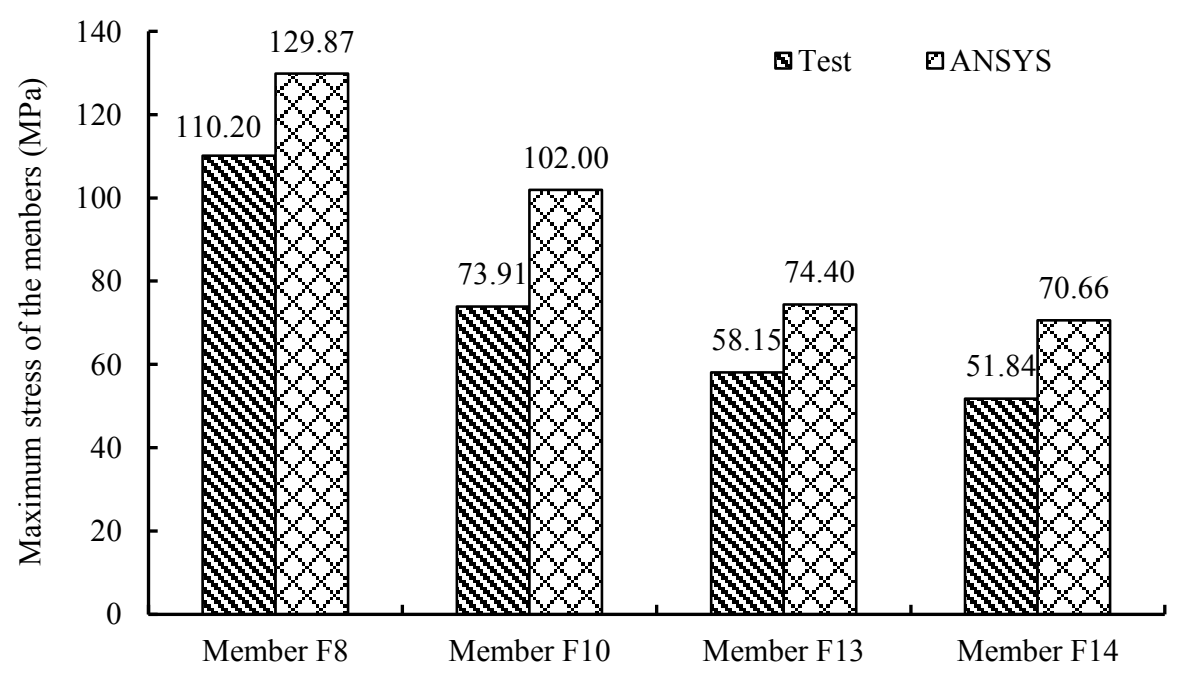

Fig. 33 The comparison of the predicted and measured maximum stresses within the cross bracing members (compressive test). 